\title{
Polymer Chemistry

\section{One-step RAFT synthesis of well-defined amphiphilic star polymers and their self-assembly in aqueous solution $\dagger$}

\author{
Christoph Herfurth, ${ }^{a}$ Paula Malo de Molina, ${ }^{b}$ Christoph Wieland, ${ }^{a}$ Sarah Rogers, ${ }^{c}$ Michael Gradzielski ${ }^{* b}$ \\ and André Laschewsky*ad
}

\author{
Received 3rd March 2012, Accepted 27th March 2012 \\ DOI: $10.1039 / \mathrm{c} 2 \mathrm{py} 20126 \mathrm{~g}$
}

\begin{abstract}
Multifunctional chain transfer agents for RAFT polymerisation were designed for the one-step synthesis of amphiphilic star polymers. Thus, hydrophobically end-capped 3- and 4-arm star polymers, as well as linear ones for reference, were made of the hydrophilic monomer $N, N$-dimethylacrylamide (DMA) in high yield with molar masses up to $150000 \mathrm{~g} \mathrm{~mol}^{-1}$, narrow molar mass distribution (PDI $\leq$ $1.2)$ and high end group functionality $(\sim 90 \%)$. The associative telechelic polymers form transient networks of interconnected aggregates in aqueous solution, thus acting as efficient viscosity enhancers and rheology modifiers, eventually forming hydrogels. The combination of dynamic light scattering (DLS), small angle neutron scattering (SANS) and rheology experiments revealed that several molecular parameters control the structure and therefore the physical properties of the aggregates. In addition to the size of the hydrophilic block (maximum length for connection) and the length of the hydrophobic alkyl chain ends (stickiness), the number of arms (functionality) proved to be a key parameter.
\end{abstract}

\section{Introduction}

Rheology modification, for instance of microemulsions, is an everyday issue for the formulation of liquid soaps, shampoos and other cosmetic products. Typical rheology modifiers used are $\alpha, \omega$-double hydrophobically end-capped hydrophilic polymers. ${ }^{1-11}$ So far, these have been mostly polyethylene oxides (PEOs) end-capped with $n$-alkyl ethers, $n$-alkyl urethanes (HEURs), and fatty acid esters or, alternatively, PEOs bearing short hydrophobic polymer end blocks. ${ }^{8}$ The thickening effect of these compounds has been studied intensely. It was found that these polymers form a transient network of interconnected micelles in water. ${ }^{1-4,8,10-15}$ The hydrophobic end groups function as "stickers" and the viscosity increase can be correlated to their length. ${ }^{1,4,8,13,15}$ In the case of linear polymers, it is obvious that

${ }^{a}$ Universität Potsdam, Institut für Chemie, Karl-Liebknecht-Str. 24-25, 14476 Potsdam-Golm, Germany

${ }^{b}$ Stranski-Laboratorium für Physikalische und Theoretische Chemie, Institut für Chemie, Technische Universität Berlin, Straße des 17. Juni 124,Sekr.TC7, 10623 Berlin, Germany.E-mail: michael.gradzielski@, tu-berlin.de

'ISIS-CCLRC Rutherford-Appleton Laboratories, Chilton OX11 OQX, $U K$

${ }^{d}$ Fraunhofer Institut für Angewandte Polymerforschung IAP, Geiselbergstr. 69, 14476 Potsdam-Golm, Germany. E-mail: andre. laschewsky@iap.fraunhofer.de

$\dagger$ Electronic supplementary information (ESI) available: SEC traces, pseudo-first order plot and plot of $M_{\mathrm{n}}$ app over conversion from kinetic experiments, SANS patterns as well as distribution function, electric field correlation function and cumulant analysis from DLS experiments. See DOI: $10.1039 / \mathrm{c} 2$ py20126g one polymer molecule can link not more than two micelles. The system becomes much more complex, once branched hydrophilic polymers with 3 or more hydrophobic sticker end groups are used. However, such studies are rare. ${ }^{4,16}$ According to the scarce literature it remains unclear, whether the topology of the amphiphilic polymers has an effect on the viscoelastic properties of their solutions or not. To shed some light on this problem, we therefore designed a series of analogous linear as well as 3- and 4-arm amphiphilic star polymers and compared their behaviour in aqueous solution.

Among the group of branched polymer architectures, star polymers combine the advantage of controlling the number and position of functionalities with a comparably straightforward synthetic access. ${ }^{17}$ For the preparation of star polymers, two general routes are employed, namely the so-called "core-first" and "arm-first" approaches. ${ }^{18-21}$ While in the latter, the synthesis of single, linear arms allows for good control over the individual length of the arms, ${ }^{22,23}$ their subsequent coupling to a core demands a highly effective and selective coupling reaction. ${ }^{22-24}$ The resulting star polymers rarely show a precise number of arms, but rather display a more or less narrow distribution of arms. $^{25,26}$ This problem is more prominent, the higher the molecular weight of the polymers is. ${ }^{18}$ In the core-first approach, the synthesis of a multiply initiating core may prove to be a challenging task ${ }^{\mathbf{1 8 , 2 7 , 2 8}}$ and - depending on the polymerisation technique employed - star-star coupling can occur. ${ }^{29,30}$ Nevertheless, when appropriate conditions are met, the core-first approach allows for good control over the number of arms and for the production of well-defined high molar mass polymers. ${ }^{18}$ 
Free radical polymerisation (FRP) does not allow the controlled fabrication of star polymers, even if some reports exemplify that controlled or living polymerisation may not always be necessary to obtain star-like structures. ${ }^{31}$ Additionally, if amphiphilicity of the resulting polymers is aspired, the synthesis of star block copolymers or controlled hydrophobic end-capping of the star polymers becomes a necessity. Both structural features are achieved using either (mostly ionic) living polymerisation techniques or the techniques of reversible-deactivation radical polymerisation (RDRP), ${ }^{32}$ often referred to as controlled radical polymerisation (CRP). Living ionic polymerisations, however, are in general infamous for their sensitivity to air, water and most functional moieties. In contrast, RDRP techniques are relatively robust and therefore allow for a convenient fabrication of amphiphilic star polymers. ${ }^{19,21,33-39}$ Radical addition fragmentation chain transfer (RAFT) polymerisation in particular tolerates a large variety of functional monomers and is relatively undemanding in terms of experimental setup, as only a chain transfer agent (CTA) is added to a classical FRP mixture. ${ }^{40,41}$

The synthesis of star polymers via the core-first approach by the RAFT process offers two possible strategies. ${ }^{19,29,42-46}$ As a RAFT CTA may contain a functional $\mathrm{R}$ as well as $\mathrm{Z}$ group, the core of the star polymer can be chosen to be part of either of them. This has important consequences for the polymerisation process. Even though the $Z$ group strategy falls into the category of the core-first approach, as the core containing multiple RAFT groups is synthesized prior to the polymerisation, the actual mechanism shares several features with the arm-first approach. As the core is part of the $\mathrm{Z}$ group, the thiocarbonyl thio moiety that introduces the RAFT equilibrium will stay at the core during the polymerisation. Hence, propagating chains have to diffuse to the centre of the forming star polymer to react with the controlling moiety and enter the RAFT equilibrium. The longer the chains get, the less probable is their diffusion to the sterically increasingly crowded center. ${ }^{44,45}$ Consequently, the more the polymerisation proceeds to higher conversions, the less control can be expected and the more incomplete stars and linear chains will be formed. This limits the practical arm length achievable by this approach. In contrast, if the core is part of the $\mathrm{R}$ group of the RAFT CTA, the chains will grow from the core and will be capped and de-capped by the thiocarbonyl thio moiety at the corona. While this approach allows for higher degrees of polymerisation and largely suppresses the formation of linear chains, it suffers from the possibility of star-star coupling reactions, the probability increasing both with conversion and number of arms. ${ }^{43}$ In order to minimize such problems, Chaffey-Millar et al. suggested a number of design criteria for the well-controlled production of star polymers using the RAFT R group approach, based on theoretical calculations backed by experimental results. ${ }^{29}$ They found that a high rate of monomer propagation combined with a small radical concentration and the use of rateretarding CTAs help in the formation of star polymers, while suppressing termination reactions leading to star-star coupling and the formation of linear chains. In our case, the RAFT R group strategy in the core-first approach enables us to prepare amphiphilic star polymers in a one step process in contrast to the reported multi-step processes. ${ }^{10,47}$ The CTAs must be tailored in such a way that they predetermine the number of arms and simultaneously introduce particular hydrophobic end groups. We employed $n$-alkyl chains with lengths of 4, 12 and 18 carbon atoms as hydrophobic end groups. The end group functionality of the polymers was varied from 2 (in the bifunctional linear polymers serving as reference) via 3 to 4 in the 3 - and 4-arm stars, so that we could investigate the influence of the number of end groups as well as of hydrophobicity on the aggregation properties (see Scheme 1). While the bifunctional CTAs 2C4-CTA, ${ }^{48}$ $2 \mathrm{C}^{2}-\mathrm{CTA}^{49}$ and $2 \mathrm{C}^{2} 8-\mathrm{CTA}^{50}$ have been described before, the various analogous multifunctional CTAs used have not been reported yet.

Current work in the field of amphiphilic, rheology modifying (star) polymers mostly relies on PEO, ${ }^{4,34}$ poly(acrylic acid), ${ }^{16,35}$ or unsubstituted poly(acrylamide) ${ }^{34}$ as the hydrophilic constituent. Here, we used $N, N$-dimethylacrylamide (DMA) as the monomer to synthesize well-defined hydrophobically end-capped hydrophilic polymers (see Scheme 2). Poly( $N, N$-dimethylacrylamide) (PDMA) is a non-ionic and highly hydrophilic polymer without LCST at ambient pressure. ${ }^{51,52}$ Despite numerous advantageous features, PDMA has found little attention as an associative telechelic so far. It is more stable against hydrolysis than the classical unsubstituted poly(acrylamide) and does not show the ageing and cross-linking issues known for PEO. In contrast to unsubstituted acrylamide, DMA is much less toxic, but can be equally polymerized using robust and easy to handle radical
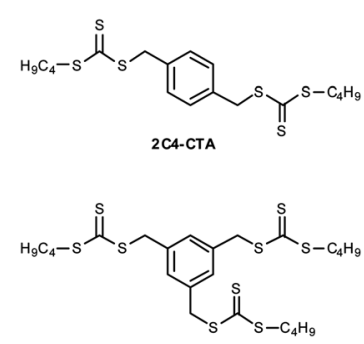

3C4-CTA

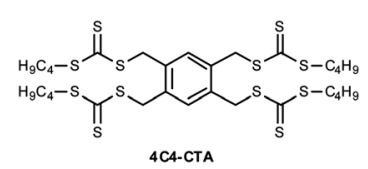

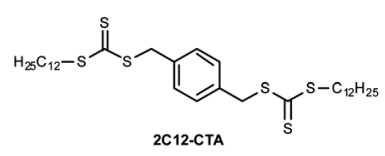

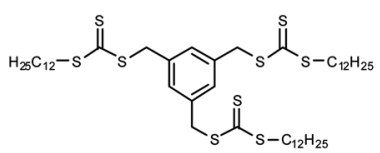

3C12-CTA

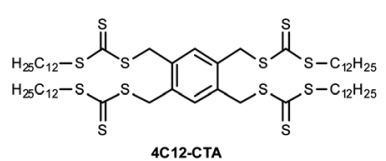

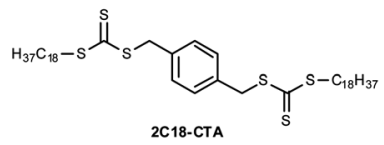

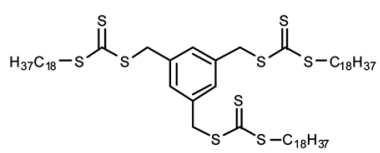

3C 18-CTA

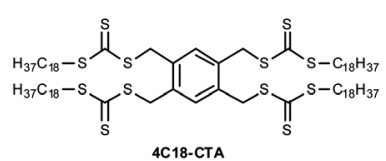

Scheme 1 Di-, tri- and tetrafunctional chain transfer agents (CTAs) synthesized. 


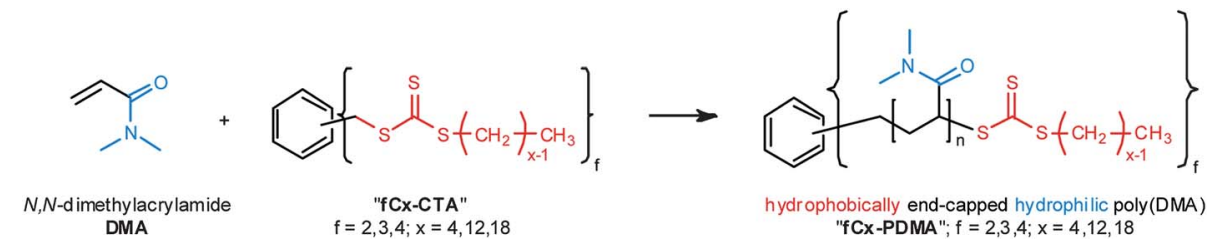

Scheme 2 One-step preparation of amphiphilic (star) polymers via RAFT polymerisation using $N, N$-dimethylacrylamide (DMA) and tailored CTAs.

polymerisation techniques in contrast to the demanding ionic polymerisation of gaseous ethylene oxide. Furthermore, DMA is known to have a high rate of propagation ${ }^{53,54}$ thus fulfilling one of the conditions postulated for an efficient production of star polymers.

\section{Experimental section}

\section{Materials}

Benzene (thiophene free, $\geq 99 \%$ ), trioctylmethylammonium chloride (Aliquat ${ }^{\mathrm{TM}}$ 336), 1,3,5-tris(bromomethyl)benzene $(97 \%)$ and 1,2,4,5-tetrakis(bromomethyl)benzene $(95 \%)$ were obtained from Aldrich. $\alpha, \alpha^{\prime}$-Dibromo- $p$-xylene ( $\geq 98.0 \%$ ), 1-butanethiol (97\%), 1-dodecanethiol ( $\geq 98 \%$ ) and potassium hydroxide $(85 \%)$ were purchased from Fluka, 1-octadecanethiol (98\%) from Acros, and carbon disulfide ( $\geq 99.9 \%$ ) from Riedel de Haën. 1, 1' Azobis(cyclohexanecarbonitrile) (V-40) was a gift from Wako. The chemicals were used as received. $N, N$-Dimethylacrylamide ( $>99.0 \%$, stabilized with MEHQ, TCI Europe) was distilled prior to use. Tetrahydrofuran ( $\geq 99 \%, 0.025 \%$ BHT) was obtained from J. T. Baker, and diethylether (99.5\%) and $n$-hexane $(95.0 \%)$ from Th. Geyer (Chemsolute).

The synthesis and molecular characterisation of 2C4-CTA, ${ }^{48}$ 2C12-CTA ${ }^{49}$ and 2C18-CTA ${ }^{50}$ are described elsewhere.

\section{Instrumentation}

NMR spectra were recorded using a Bruker Avance 300 NMR spectrometer operating at $300 \mathrm{MHz}$ for ${ }^{1} \mathrm{H}$ measurements and $75 \mathrm{MHz}$ for ${ }^{13} \mathrm{C}$ measurements. Chemical shifts $\delta$ are given in ppm referring to tetramethylsilane (TMS).

UV/VIS spectra were recorded on a Varian Cary 1E spectrometer using quartz sample cells with an optical path length of $1 \mathrm{~cm}$. From the extinction $E$ at $309 \mathrm{~nm}$ of the polymer solutions in $\mathrm{CH}_{3} \mathrm{CN}$, the molar mass $M_{\mathrm{n}}^{\mathrm{UV}}$ can be calculated using eqn (1) ${ }^{50}$ where $\varepsilon\left[\mathrm{L} \mathrm{mol}^{-1} \mathrm{~cm}^{-1}\right]$ is the molar extinction coefficient, $c$ [g L $\left.{ }^{-1}\right]$ is the concentration of the polymer and $d[\mathrm{~cm}]$ is the optical path length of the light inside the sample cell:

$$
M_{\mathrm{n}}^{\mathrm{UV}}=\frac{\varepsilon c d}{E}
$$

The molar extinction coefficient $\varepsilon$ of the trithiocarbonate chromophore substituted with a PDMA-analogous R group and $n$-butyl $\mathrm{Z}$ group was determined as $15500 \mathrm{~L} \mathrm{~mol}^{-1} \mathrm{~cm}^{-1}$ in acetonitrile. ${ }^{50}$ Assuming additivity, we multiplied this $\varepsilon$ value by the number of end groups in the various PDMA samples, thus yielding $\varepsilon=31000 \mathrm{~L} \mathrm{~mol}^{-1} \mathrm{~cm}^{-1}$ for the bifunctional linear reference polymers, $\varepsilon=46500 \mathrm{~L} \mathrm{~mol}^{-1} \mathrm{~cm}^{-1}$ for 3-arm trifunctional star polymers, and $\varepsilon=62000 \mathrm{~L} \mathrm{~mol}^{-1} \mathrm{~cm}^{-1}$ for 4-arm tetrafunctional star polymers.

Elemental analysis used a Vario ELIII analyzer from Elementar Analysensysteme, Germany.

SEC measurements were done with two different systems. The SEC setup for measurements in a mixture of $80 \% 0.05 \mathrm{M} \mathrm{Na}_{2} \mathrm{SO}_{4}$ in de-ionised water and $20 \%$ acetonitrile consisted of a four channel degasser SCM 400 from Spectra Physics, an isocratic pump P 1000 from Spectra Physics, a set of TSK-GEL PW columns $(7.5 \times 300 \mathrm{~mm})$ from TOSOH Biosep (Guard, 6000, 5000, 4000, 3000), a Dawn DSP MALLS detector from Wyatt, a UV/VIS detector UV 2000 from Spectra Physics and a dual detector for viscosity and refractive index $\eta$-1002 from WGE Dr

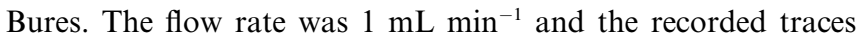
were analyzed using Astra 4.9 software from Wyatt. The $\mathrm{d} n / \mathrm{d} c$ value used for poly $(N, N$-dimethylacrylamide $)$ in a mixture of $80 \% 0.05 \mathrm{M} \mathrm{Na}_{2} \mathrm{SO}_{4}$ in de-ionised water and $20 \%$ acetonitrile was reported to be $0.161 \mathrm{~mL} \mathrm{~g}^{-1} .^{53}$

SEC measurements in $N$-methyl-2-pyrrolidone (NMP) + $0.05 \mathrm{M} \mathrm{LiBr}$ were performed at $70^{\circ} \mathrm{C}$ with a flow rate of $0.8 \mathrm{~mL}$ $\mathrm{min}^{-1}$ using a set of two PSS-GRAM columns $(300 \times 8 \mathrm{~mm}$, $100 \AA$ and $1000 \AA$ porosity, $7 \mu \mathrm{m}$ particle size) and a TSP apparatus (Thermo Separation Products, Thermo-Finnigan $\mathrm{GmbH}$ ) equipped with a Shodex RI-71 refractive index detector and a TSP UV detector. The traces were analyzed using linear polystyrene standards (PSS, Mainz/Germany) for calibration.

The small angle neutron scattering (SANS) measurements were performed at the pulsed neutron source ISIS at the Rutherford Appleton Laboratory, England on the SANS2D time-of flight instrument. The sample-to-detector distance as well as the collimation distance was $4 \mathrm{~m}$. The wavelength of neutrons used was from 2 to $14 \AA$. Accordingly, a range of the magnitude of the scattering vectors of $0.05<Q<8 \mathrm{~nm}^{-1}$ was covered. The SANS data were treated according to standard procedures for absolute scaling, radial averaging and background subtraction. The absolute scaling was done with a monodisperse, partially deuterated polymer blend. Detection efficiency was not taken into account. SANS measurements of the aqueous solutions of 1 and $5 \mathrm{wt} \%$ of samples 10 (3C12-PDMA) and 15 (4C12PDMA) were performed at the spectrometer PAXY at the Laboratoire Léon Brillouin (LLB, CEA-CNRS, Saclay, France) with a neutron wavelength of $5 \AA$ and sample-to-detector distances of 1.145 and $5.045 \mathrm{~m}$. The covered range of the magnitude of the scattering vectors was from $0.09<Q<$ $3.3 \mathrm{~nm}^{-1}$ (more details are given elsewhere ${ }^{55}$ ). For molar mass determination, the polymers were dissolved in THF-d8. THF is a good solvent for the polymer and correspondingly the obtained scattering curves were fitted with a generalized Gauss coil form factor that is given as: ${ }^{56}$ 


$$
\begin{aligned}
& I(Q)=I(0) \\
& \frac{U^{1 / 2 \nu} \Gamma(1 / 2 \nu, 0)-\Gamma(1 / \nu, 0)-U^{1 / 2 \nu} \Gamma(1 / 2 \nu, U)+\Gamma(1 / \nu, U)}{\nu U^{\nu}}
\end{aligned}
$$

$$
U=(2 \nu+1)(2 \nu+2) \frac{Q^{2} R_{\mathrm{g}}{ }^{2}}{6} \text { and } \Gamma(a, x)=\int_{x}^{\infty} t^{a-t} \exp (-t) \mathrm{d} t
$$

where $T$ is the gamma function, $\nu$ the excluded volume parameter from the Flory mean field theory (being 0.5 for ideal theta conditions and around 0.6 for the real theta case), and $R_{\mathrm{g}}$ the radius of gyration. From $I(0)$ the molecular weight can directly be calculated via:

$$
M_{\mathrm{w}}=\frac{\rho^{2} N_{\mathrm{Av}}}{\Delta \rho^{2}} \lim _{c_{\mathrm{g}} \rightarrow 0}\left(\frac{I(0)}{c_{\mathrm{g}}}\right)
$$

where $\rho$ is the polymer density $\left(1.05 \mathrm{~g} \mathrm{~cm}^{-3}\right), N_{\mathrm{Av}}$ the Avogadro constant, $\Delta \rho$ the difference of the scattering length densities of polymer and solvent, and $c_{\mathrm{g}}$ the weight concentration of polymer.

Dynamic Light Scattering (DLS) experiments were performed at $25^{\circ} \mathrm{C}$ using a setup consisting of an ALV/LSE-5004 correlator, an ALV CGS-3 goniometer and a He-Ne Laser with a wavelength of $632.8 \mathrm{~nm}$. Cylindrical sample cells were placed in an index matching toluene vat. Intensity correlation functions were recorded under different angles between $50^{\circ}$ and $130^{\circ}$.

Oscillating rheology measurements used a Bohlin Gemini 150 rheometer equipped with a high-frequency extension with a piezo rotary vibrator. ${ }^{57} \mathrm{~A}$ plate-plate geometry of aluminium was used with a diameter of $40 \mathrm{~mm}$. This set-up then allows for measurements from 10 up to $2000 \mathrm{~Hz}$. This overlaps with the conventional set-up in which frequencies of $0.001-20 \mathrm{~Hz}$ can be covered, which was employed as well for all samples investigated.

\section{Synthesis of the chain transfer agents}

All chain transfer agents (CTAs) were synthesized under nitrogen atmosphere by a general protocol, adopting a procedure from Degani et al. ${ }^{58}$ Aliquat $^{\mathrm{TM}} 336(0.1 \mathrm{~mL})$ was added to aqueous $\mathrm{KOH}(20 \mathrm{wt} \%)$ and the solution was purged with nitrogen. The thiol was added and the mixture was stirred at room temperature for $15 \mathrm{~min}$. Then, carbon disulfide was added and the mixture was stirred at room temperature for another 15 min. Finally, a solution of the chosen multifunctional benzyl bromide in THF $(5 \mathrm{~mL})$ was added and the mixture was stirred for $2 \mathrm{~h}$ at $70{ }^{\circ} \mathrm{C}$. The mixture was stirred overnight at room temperature to allow the reaction to complete. Then, dichloromethane was added, the organic phase was washed with $0.1 \mathrm{M}$ $\mathrm{HCl}$ and with water. The organic phase was dried over $\mathrm{MgSO}_{4}$ and the solvent was removed under reduced pressure. The residual raw product was purified by column chromatography on silica gel 60 using dichloromethane- $n$-hexane $1: 10$ as eluent.

1,3,5-Tris(butylsulfanylthiocarbonylsulfanylmethyl)benzene (3C4-CTA). 3C4-CTA was synthesized starting from 1-butanethiol $(0.81 \mathrm{~g}, 9 \mathrm{mmol}), \mathrm{KOH}(0.60 \mathrm{~g}, 9 \mathrm{mmol})$, carbon disulfide $(0.69 \mathrm{~g}, 9 \mathrm{mmol})$ and 1,3,5-tris(bromomethyl)benzene (1.0 g, 2.80 mmol). Yield: $0.78 \mathrm{~g}$ (1.26 mmol, 45.3\%).
${ }^{1} \mathrm{H} \mathrm{NMR}\left(\mathrm{CDCl}_{3}\right) \delta[\mathrm{ppm}]=0.94\left(\mathrm{t}, \mathrm{CH}_{3}, 9 \mathrm{H}, J=7.5 \mathrm{~Hz}\right), 1.38-$ $1.50\left(\mathrm{~m}, \mathrm{CH}_{2}-\mathrm{CH}_{3}, 6 \mathrm{H}\right), 1.64-1.74\left(\mathrm{~m}, \mathrm{CH}_{2}-\mathrm{CH}_{2}, 6 \mathrm{H}\right), 3.38$ (t, S$\mathrm{CH}_{2}-\mathrm{CH}_{2}, 6 \mathrm{H}, \mathrm{J}=7.5 \mathrm{~Hz}$ ), 4.54(s, Ph-CH $\left.-\mathrm{S}, 6 \mathrm{H}\right), 7.21(\mathrm{~s}, \mathrm{Ph}, 3 \mathrm{H})$.

${ }^{13} \mathrm{C} \mathrm{NMR}\left(\mathrm{CDCl}_{3}\right) \delta[\mathrm{ppm}]=13.8\left(\mathrm{CH}_{3}\right), 22.2\left(\mathrm{CH}_{2}-\mathrm{CH}_{3}\right)$, $30.2\left(\mathrm{CH}_{2}-\mathrm{CH}_{2}\right), 37.0\left(\mathrm{~S}-\mathrm{CH}_{2}-\mathrm{CH}_{2}\right), 40.9\left(\mathrm{Ph}-\mathrm{CH}_{2}-\mathrm{S}\right), 129.5$ (ar$C-\mathrm{H}), 136.6\left(\right.$ ar $\left.-C-\mathrm{CH}_{2}\right), 223.4(-\mathrm{C}=\mathrm{S})$.

Anal. calcd for $\mathrm{C}_{24} \mathrm{H}_{36} \mathrm{~S}_{9}$ : C, $47.0 \%, \mathrm{H}, 5.9 \%$, S, 47.1\%; found: C, $47.4 \%, \mathrm{H}, 5.8 \%, \mathrm{~S}, 46.35 \%$.

1,2,4,5-Tetrakis(butylsulfanylthiocarbonylsulfanylmethyl) benzene (4C4-CTA). 4C4-CTA was synthesized starting from 1butanethiol (0.90 g, $10 \mathrm{mmol}), \mathrm{KOH}(0.66 \mathrm{~g}, 10 \mathrm{mmol})$, carbon disulfide $(0.76 \mathrm{~g}, 10 \mathrm{mmol})$ and 1,2,4,5-tetrakis(bromomethyl) benzene (1.0 g, $2.22 \mathrm{mmol})$. Yield: $0.43 \mathrm{~g}(0.54 \mathrm{mmol}, 24.7 \%)$.

${ }^{1} \mathrm{H} \mathrm{NMR}\left(\mathrm{CDCl}_{3}\right) \delta[\mathrm{ppm}]=0.94\left(\mathrm{t}, \mathrm{CH}_{3}, 12 \mathrm{H}, J=7.5 \mathrm{~Hz}\right)$, 1.38-1.50 (m, $\left.\mathrm{CH}_{2}-\mathrm{CH}_{3}, 8 \mathrm{H}\right), 1.65-1.74\left(\mathrm{~m}, \mathrm{CH}_{2}-\mathrm{CH}_{2}, 8 \mathrm{H}\right), 3.38$ (t, S-CH $\left.\mathrm{CH}_{2}-\mathrm{CH}_{2}, 8 \mathrm{H}, J=7.5 \mathrm{~Hz}\right), 4.61\left(\mathrm{~s}, \mathrm{Ph}-\mathrm{CH}_{2}-\mathrm{S}, 8 \mathrm{H}\right), 7.36$ (s, $\mathrm{Ph}, 2 \mathrm{H})$.

${ }^{13} \mathrm{C} \mathrm{NMR}\left(\mathrm{CDCl}_{3}\right) \delta[\mathrm{ppm}]=13.7\left(\mathrm{CH}_{3}\right), 22.2\left(\mathrm{CH}_{2}-\mathrm{CH}_{3}\right)$, $30.2\left(\mathrm{CH}_{2}-\mathrm{CH}_{2}\right), 37.1\left(\mathrm{~S}-\mathrm{CH}_{2}-\mathrm{CH}_{2}\right), 38.4\left(\mathrm{Ph}-\mathrm{CH}_{2}-\mathrm{S}\right), 133.6($ ar$C$-H), 134.4 (ar- $\left.C-\mathrm{CH}_{2}\right), 222.9(-C=\mathrm{S})$.

Anal. calcd for $\mathrm{C}_{30} \mathrm{H}_{46} \mathrm{~S}_{12}$ : C, 45.5\%, H, 5.8\%, S, 48.6\%; found: C, $45.65 \%, \mathrm{H}, 5.5 \%, \mathrm{~S}, 49.15 \%$.

1,3,5-Tris(dodecylsulfanylthiocarbonylsulfanylmethyl)benzene (3C12-CTA). 3C12-CTA was synthesized starting from 1dodecanethiol (2.02 g, $10 \mathrm{mmol}), \mathrm{KOH}(0.66 \mathrm{~g}, 10 \mathrm{mmol})$, carbon disulfide $(0.76 \mathrm{~g}, 10 \mathrm{mmol})$ and 1,3,5-tris(bromomethyl)benzene (1.0 g, $2.80 \mathrm{mmol})$. Yield: $1.44 \mathrm{~g}$ (1.52 mmol, 54.1\%).

${ }^{1} \mathrm{H} \mathrm{NMR}\left(\mathrm{CDCl}_{3}\right) \delta[\mathrm{ppm}]=0.87\left(\mathrm{t}, \mathrm{CH}_{3}, 9 \mathrm{H}, J=7.5 \mathrm{~Hz}\right)$, 1.25-1.41 (m, $\left.\left(\mathrm{CH}_{2}\right)_{9}-\mathrm{CH}_{3}, 54 \mathrm{H}\right), 1.64-1.73\left(\mathrm{~m}, \mathrm{CH}_{2}-\left(\mathrm{CH}_{2}\right)_{9}\right.$, $6 \mathrm{H}), 3.35$ (t, S-CH$\left.-\mathrm{CH}_{2}, 6 \mathrm{H}, J=7.5 \mathrm{~Hz}\right), 4.52$ (s, $\mathrm{Ph}-\mathrm{CH}_{2}-\mathrm{S}$, $6 \mathrm{H}), 7.19$ (s, Ph, 3H).

${ }^{13} \mathrm{C} \mathrm{NMR}\left(\mathrm{CDCl}_{3}\right) \delta[\mathrm{ppm}]=13.9\left(\mathrm{CH}_{3}\right), 22.5\left(\mathrm{CH}_{2}-\mathrm{CH}_{3}\right), 28.7-$ $29.4\left(\left(\mathrm{CH}_{2}\right)_{8}-\mathrm{CH}_{2}\right), 31.7\left(\mathrm{CH}_{2}-\left(\mathrm{CH}_{2}\right)_{8}\right), 37.0\left(\mathrm{~S}-\mathrm{CH}_{2}-\mathrm{CH}_{2}\right), 40.5$ ( $\left.\mathrm{Ph}-\mathrm{CH}_{2}-\mathrm{S}\right), 129.2$ (ar-C-H), $136.2\left(\right.$ ar $\left.-\mathrm{C}-\mathrm{CH}_{2}\right), 223.0(-\mathrm{C}=\mathrm{S})$.

Anal. calcd for $\mathrm{C}_{48} \mathrm{H}_{84} \mathrm{~S}_{9}$ : C, 60.7\%, H, 8.9\%, S, 30.4\%; found: C, $60.9 \%, \mathrm{H}, 8.7 \%$, S, 30.5\%.

1,2,4,5-Tetrakis(dodecylsulfanylthiocarbonylsulfanylmethyl) benzene (4C12-CTA). 4C12-CTA was synthesized starting from 1dodecanethiol (4.04 g, $20 \mathrm{mmol}), \mathrm{KOH}$ (1.32 g, $20 \mathrm{mmol}$ ), carbon disulfide (1.52 g, $20 \mathrm{mmol})$ and 1,2,4,5-tetrakis(bromomethyl) benzene (1.0 g, $2.22 \mathrm{mmol})$. Yield: $0.98 \mathrm{~g}(0.80 \mathrm{mmol}, 35.6 \%)$.

${ }^{1} \mathrm{H} \mathrm{NMR}\left(\mathrm{CDCl}_{3}\right) \delta[\mathrm{ppm}]=0.86\left(\mathrm{t}, \mathrm{CH}_{3}, 12 \mathrm{H}, J=6.0 \mathrm{~Hz}\right)$, $1.24-1.45\left(\mathrm{~m},\left(\mathrm{CH}_{2}\right)_{9}-\mathrm{CH}_{3}, 72 \mathrm{H}\right), 1.63-1.73\left(\mathrm{~m}, \mathrm{CH}_{2}-\left(\mathrm{CH}_{2}\right)_{9}\right.$, $8 \mathrm{H}), 3.35$ (t, S-CH$\left.-\mathrm{CH}_{2}, 8 \mathrm{H}, J=7.5 \mathrm{~Hz}\right), 4.59$ (s, $\mathrm{Ph}-\mathrm{CH}_{2}-\mathrm{S}$, $8 \mathrm{H}), 7.34$ (s, Ph, 2H).

${ }^{13} \mathrm{C} \mathrm{NMR}\left(\mathrm{CDCl}_{3}\right) \delta[\mathrm{ppm}]=14.3\left(\mathrm{CH}_{3}\right), 22.9\left(\mathrm{CH}_{2}-\mathrm{CH}_{3}\right), 28.2-$ $29.9\left(\left(\mathrm{CH}_{2}\right)_{8}-\mathrm{CH}_{2}\right), 32.2\left(\mathrm{CH}_{2}-\left(\mathrm{CH}_{2}\right)_{8}\right), 37.5\left(\mathrm{~S}-\mathrm{CH}_{2}-\mathrm{CH}_{2}\right), 38.5$ ( $\left.\mathrm{Ph}-\mathrm{CH}_{2}-\mathrm{S}\right), 131.8$ (ar- $\left.C-\mathrm{H}\right), 134.5\left(\right.$ ar $\left.-C-\mathrm{CH}_{2}\right), 223.0(-C=\mathrm{S})$.

Anal. calcd for $\mathrm{C}_{62} \mathrm{H}_{110} \mathrm{~S}_{12}$ : C, $60.0 \%, \mathrm{H}, 8.9 \%, \mathrm{~S}, 31.0 \%$; found: C, $60.3 \%, \mathrm{H}, 9.3 \%, \mathrm{~S}, 30.7 \%$.

1,3,5-Tris(octadecylsulfanylthiocarbonylsulfanylmethyl)benzene (3C18-CTA). 3C18-CTA was synthesized starting from 1-octadecanethiol (2.87 g, $10 \mathrm{mmol}), \mathrm{KOH}$ (0.66 g, $10 \mathrm{mmol})$, carbon disulfide (0.76 g, $10 \mathrm{mmol})$ and 1,3,5-tris(bromomethyl)-benzene $(1.0 \mathrm{~g}, 2.80 \mathrm{mmol})$. The product precipitated from 
dichloromethane at $-18{ }^{\circ} \mathrm{C}$ and was pure according to NMR analysis. Yield: $3.10 \mathrm{~g}$ (2.58 mmol, 92.1\%).

${ }^{1} \mathrm{H} \mathrm{NMR}\left(\mathrm{CDCl}_{3}\right) \delta[\mathrm{ppm}]=0.86\left(\mathrm{t}, \mathrm{CH}_{3}, 9 \mathrm{H}, J=6.0 \mathrm{~Hz}\right)$, 1.24-1.45 (m, $\left.\left(\mathrm{CH}_{2}\right)_{15}-\mathrm{CH}_{3}, 90 \mathrm{H}\right), 1.63-1.73\left(\mathrm{~m}, \mathrm{CH}_{2}-\left(\mathrm{CH}_{2}\right)_{9}\right.$, $6 \mathrm{H}), 3.35$ (t, S-CH$\left.-\mathrm{CH}_{2}, 6 \mathrm{H}, J=7.5 \mathrm{~Hz}\right), 4.53$ (s, $\mathrm{Ph}-\mathrm{CH}_{2}-\mathrm{S}$, $6 \mathrm{H}), 7.19$ (s, Ph, 3H).

${ }^{13} \mathrm{C} \mathrm{NMR}\left(\mathrm{CDCl}_{3}\right) \delta[\mathrm{ppm}]=14.4\left(\mathrm{CH}_{3}\right), 23.0\left(\mathrm{CH}_{2}-\mathrm{CH}_{3}\right)$, 28.3-30.0 $\left(\left(\mathrm{CH}_{2}\right)_{8}-\mathrm{CH}_{2}\right), 32.2 \quad\left(\mathrm{CH}_{2}-\left(\mathrm{CH}_{2}\right)_{8}\right), 37.5 \quad\left(\mathrm{~S}-\mathrm{CH}_{2^{-}}\right.$ $\left.\mathrm{CH}_{2}\right), 41.0\left(\mathrm{Ph}-\mathrm{CH}_{2}-\mathrm{S}\right), 129.7$ (ar- $\left.C-\mathrm{H}\right), 136.7$ (ar- $\left.C-\mathrm{CH}_{2}\right)$, $223.5(-C=\mathrm{S})$.

Anal. calcd for $\mathrm{C}_{66} \mathrm{H}_{120} \mathrm{~S}_{9}$ : C, 65.9\%, H, 10.1\%, S, 24.0\%; found: C, $65.9 \%, \mathrm{H}, 10.1 \%, \mathrm{~S}, 24.7 \%$.

1,2,4,5-Tetrakis(octadecylsulfanylthiocarbonylsulfanylmethyl) benzene (4C18-CTA). 4C18-CTA was synthesized starting from 1-octadecanethiol $(5.10 \mathrm{~g}, 17.8 \mathrm{mmol})$, tetrabutylammonium hydroxide $(11.68 \mathrm{~g}, 18 \mathrm{mmol})$ in $\mathrm{H}_{2} \mathrm{O}(40 \mathrm{wt} \%)$, carbon disulfide (1.35 g, $17.8 \mathrm{mmol})$ and 1,2,4,5-tetrakis(bromomethyl)benzene $(1.0 \mathrm{~g}, 2.22 \mathrm{mmol})$. To prevent precipitation of the intermediate 2- and 3-functional CTAs, the reaction was carried out in a mixture of water, THF and benzene in a ratio of $\mathrm{v} / \mathrm{v} / \mathrm{v}=$ $1: 1: 1$. In addition, the reaction mixture was kept at $70{ }^{\circ} \mathrm{C}$ overnight. Yield: $0.97 \mathrm{~g}(0.62 \mathrm{mmol}, 28.0 \%)$.

${ }^{1} \mathrm{H} \mathrm{NMR}\left(\mathrm{CDCl}_{3}\right) \delta[\mathrm{ppm}]=0.86\left(\mathrm{t}, \mathrm{CH}_{3}, 12 \mathrm{H}, J=6.0 \mathrm{~Hz}\right)$, 1.24-1.45 (m, $\left.\left(\mathrm{CH}_{2}\right)_{15}-\mathrm{CH}_{3}, 120 \mathrm{H}\right), 1.63-1.73\left(\mathrm{~m}, \mathrm{CH}_{2}-\left(\mathrm{CH}_{2}\right)_{15}\right.$, $8 \mathrm{H}), 3.34$ (t, S-CH$\left.-\mathrm{CH}_{2}, 8 \mathrm{H}, J=7.5 \mathrm{~Hz}\right), 4.59$ (s, Ph- $\mathrm{CH}_{2}-\mathrm{S}$, $8 \mathrm{H}), 7.34$ (s, Ph, 2H).

${ }^{13} \mathrm{C} \mathrm{NMR}\left(\mathrm{CDCl}_{3}\right) \delta[\mathrm{ppm}]=14.3\left(\mathrm{CH}_{3}\right), 22.9\left(\mathrm{CH}_{2}-\mathrm{CH}_{3}\right)$, $28.2-29.9\left(\left(\mathrm{CH}_{2}\right)_{15}-\mathrm{CH}_{2}\right), 32.2\left(\mathrm{CH}_{2}-\left(\mathrm{CH}_{2}\right)_{15}\right), 37.5\left(\mathrm{~S}-\mathrm{CH}_{2^{-}}\right.$ $\left.\mathrm{CH}_{2}\right), 38.5\left(\mathrm{Ph}-\mathrm{CH}_{2}-\mathrm{S}\right), 133.7$ (ar-C-H), 134.5 (ar- $\left.C-\mathrm{CH}_{2}\right), 223.0$ $(-C=\mathrm{S})$.

Anal. calcd for $\mathrm{C}_{86} \mathrm{H}_{158} \mathrm{~S}_{12}$ : C, 65.5\%, H, 10.1\%, S, 24.4\%; found: C, $65.6 \%, \mathrm{H}, 10.4 \%, \mathrm{~S}, 24.3 \%$.

\section{RAFT polymerisations}

All RAFT polymerisations followed a general protocol. The required amount of CTA was calculated using eqn (5), where $n$ is the number of moles, $X$ is the aspired conversion and $\mathrm{DP}_{n}$ is the aspired degree of polymerisation:

$$
n(\mathrm{CTA})=\frac{n(\mathrm{DMA}) X}{\mathrm{DP}_{\mathrm{n}}}
$$

The amount of the initiator $\mathrm{V}-40$ is calculated to give a ratio of CTA to initiator of $\mathrm{n} / \mathrm{n}=10: 1$.

For a typical polymerisation aspiring a 3-arm C12 end-capped star polymer with $\mathrm{DP}_{n}=500$ and $X=0.5, N, N$-dimethylacrylamide ( $4 \mathrm{~g}, 0.04 \mathrm{~mol}, 4.16 \mathrm{~mL}$ ) is dissolved in $5 \mathrm{~mL}$ of benzene and 3C12-CTA (38.3 mg, $0.04 \mathrm{mmol})$ in benzene $(2 \mathrm{~mL})$ is added. A stock solution of $1,1^{\prime}$-azobis(cyclohexanecarbonitrile) in benzene is prepared $\left(2 \mathrm{mg} \mathrm{mL}^{-1}\right) .1 \mathrm{~mL}$ of this solution (equivalent to $4 \times 10^{-3} \mathrm{mmol}$ initiator) is added to the polymerisation solution. The homogeneous reaction mixture is purged with nitrogen for $45 \mathrm{~min}$ and immersed into a preheated oil bath with a temperature of $90{ }^{\circ} \mathrm{C}$. After stirring for $3 \mathrm{~h}$ at $90{ }^{\circ} \mathrm{C}$, the reaction is stopped by opening the flask to the air and cooling with liquid nitrogen. The polymer is isolated by precipitation into diethylether, dissolved in water, lyophilized and weighed.
The theoretically expected molar mass $M_{\mathrm{n}}{ }^{\text {theo }}$ is calculated using eqn (6), where $M_{\mathrm{CTA}}$ is the molar mass of the CTA, $X$ is the conversion of the monomer, $M_{\mathrm{DMA}}$ is the molar mass of the monomer and $n$ is the number of moles, respectively:

$$
M_{\mathrm{n}}^{\text {theo }}=M_{\mathrm{CTA}}+X M_{\mathrm{DMA}} \frac{n(\mathrm{DMA})}{n(\mathrm{CTA})}
$$

\section{Kinetic experiments}

For kinetic experiments, the polymerisation mixtures were prepared as described above. Samples were drawn after predetermined time intervals via a syringe under positive pressure of nitrogen. The samples were quenched by exposure to air and cooling with liquid nitrogen. Monomer conversion was determined by ${ }^{1} \mathrm{H}$ NMR spectroscopy diluting the samples with benzene-d6. The conversion was determined by comparing the signals of the vinylic protons to those of the methyl protons. The samples were worked up as described above and analyzed by SEC.

\section{Results and discussion}

\section{Synthesis and characterisation of the polymers}

For synthesising the CTAs, $n$-alkylthiols of the desired length, carbon disulfide and the specific multifunctional benzyl bromides were used as building blocks. ${ }^{58}$ Though the reaction is a priori straightforward, we found that the yield of the reaction decreased, the longer the $n$-alkylthiol and the higher the functionality was. Hence, for $n$-octadecylthiol-CTAs a mixture of solvents (water, THF, and benzene) had to be used to enable the reaction. This finding is attributed both to the steric shielding of the thiol-group on the longer $n$-alkylthiols, thus reducing the reactivity, and to the increased tendency of the alkyl-chains to crystallize and consequently precipitate from the reaction mixture.

The conditions for the preparation of the polymers were chosen taking the suggestions by Chaffey-Millar et al. into account. ${ }^{29}$ Accordingly, polymerisations were conducted at the elevated temperature of $90{ }^{\circ} \mathrm{C}$, to favour fast propagation. In order to keep the delivery of radicals sufficiently low, we employed the initiator 1,1'-azobis(cyclohexanecarbonitrile), which has a half-life time of $10 \mathrm{~h}$ at $88^{\circ} \mathrm{C}$. Furthermore, benzene, which is virtually inert to radical chain transfer reactions, was added as solvent to ensure proper dissolution of the monomer, the CTA and final polymer.

Under these conditions we were able to prepare amphiphilic star polymers from DMA in one step with high yields and good control over a wide range of molar masses (see Table 1). The polymers were characterized by various methods. Due to their amphiphilic character, size exclusion chromatography (SEC) of the polymers required the use of two set-ups. In the good solvent $N$-methyl-2-pyrrolidone (NMP), we found exclusively narrow monomodal molar mass distributions (PDI $\leq 1.2$ ). This is a first indication of the good control over the reaction (see Table 1). Despite the calibration of the SEC set-up by linear polystyrene standards, the apparent molar masses $M_{\mathrm{n}}$ app obtained agree rather well with the theoretically expected $M_{\mathrm{n}}{ }^{\text {theo }}$ for shorter chains $\left(M_{\mathrm{n}} \leq 50 \mathrm{~kg} \mathrm{~mol}{ }^{-1}\right)$. With increasing chain length, however, the deviation of $M_{\mathrm{n}}{ }^{\text {app }}$ from $M_{\mathrm{n}}{ }^{\text {theo }}$ is increasingly visible 
Table 1 Parameters and characterisation results for RAFT-polymerisations of DMA in benzene at $90{ }^{\circ} \mathrm{C}$ for $3 \mathrm{~h}$ using CTA : V-40 = $10: 1$

\begin{tabular}{|c|c|c|c|c|c|c|c|c|c|c|c|c|}
\hline Entry & CTA & $\begin{array}{l}\text { DMA/ } \\
\text { CTA }\end{array}$ & Yield $^{a}(\%)$ & $\begin{array}{l}M_{\mathrm{n}}^{\text {theo } b} \\
\left(\mathrm{~kg} \mathrm{~mol}^{-1}\right)\end{array}$ & $\begin{array}{l}M_{\mathrm{n}}^{\text {app } c} \\
\left(\mathrm{~kg} \mathrm{~mol}^{-1}\right)\end{array}$ & $\begin{array}{l}\mathrm{PDI}^{c} \\
M_{\mathrm{w}} / M_{\mathrm{n}} \\
\end{array}$ & $\begin{array}{l}M_{\mathrm{n}} \text { MALLS } d \\
\left(\mathrm{~kg} \mathrm{~mol}^{-1}\right)\end{array}$ & $\begin{array}{l}M_{\mathrm{w}}{ }^{\text {MALLS } d} \\
\left(\mathrm{~kg} \mathrm{~mol}^{-1}\right)\end{array}$ & $\begin{array}{l}\mathrm{PDI}^{d} \\
M_{\mathrm{w}} / M_{\mathrm{n}}\end{array}$ & $\mathrm{Z}$ group $^{e}(\%)$ & $\begin{array}{l}M_{\mathrm{w}}^{\text {SANS } g} \\
\left(\mathrm{~kg} \mathrm{~mol}^{-1}\right)\end{array}$ & $R_{\mathrm{g}}{ }^{h}(\mathrm{~nm})$ \\
\hline 1 & $2 \mathrm{C} 4$ & 1000 & 88 & 87.2 & 62.5 & 1.16 & 83.7 & 95.7 & 1.14 & 84 & 120 & 9.4 \\
\hline 3 & $2 \mathrm{C} 12$ & 500 & 96 & 48.2 & 43.5 & 1.08 & 58.6 & 61.4 & 1.05 & 77 & 73 & 7.4 \\
\hline 4 & $2 \mathrm{C} 12$ & 1000 & 93 & 92.6 & 73.7 & 1.19 & 112 & 121 & 1.08 & 90 & 158 & 11.2 \\
\hline 5 & $2 \mathrm{C} 18$ & 250 & 93 & 24.0 & 23.2 & 1.07 & ${ }_{f}^{f}$ & ${ }^{f}$ & ${ }^{f}$ & 91 & - & - \\
\hline 6 & $2 \mathrm{C} 18$ & 1000 & 98 & 98.0 & 72.2 & 1.17 & ${ }^{f}$ & ${ }^{f}$ & ${ }^{f}$ & 88 & 186 & 10.9 \\
\hline 9 & $3 \mathrm{C} 12$ & 750 & 94 & 71.0 & 56.7 & 1.12 & 80.7 & 84.1 & 1.04 & 98 & 104 & 9.8 \\
\hline 10 & $3 \mathrm{C} 12$ & 1000 & 87 & 87.4 & 55.7 & 1.21 & 104 & 116 & 1.11 & 92 & 108 & 10.0 \\
\hline 11 & $3 \mathrm{C} 18$ & 375 & 97 & 37.6 & 31.1 & 1.08 & $-f$ & $f^{f}$ & $f^{f}$ & 97 & - & - \\
\hline 12 & $3 \mathrm{C} 18$ & 1000 & 83 & 83.0 & 52.6 & 1.15 & ${ }^{f}$ & ${ }^{f}$ & $f$ & 92 & 109 & 9.9 \\
\hline 13 & $4 C 4$ & 1000 & 85 & 85.0 & 61.3 & 1.11 & 104 & 111 & 1.07 & 89 & 128 & 10.7 \\
\hline 14 & $4 \mathrm{C} 12$ & 500 & 87 & 44.4 & 40.9 & 1.07 & $f^{f}$ & ${ }^{f}$ & ${ }^{f}$ & 77 & - & - \\
\hline 15 & $4 \mathrm{C} 12$ & 1000 & 97 & 97.6 & 63.3 & 1.12 & 111 & 118 & 1.06 & 96 & 131 & 10.5 \\
\hline
\end{tabular}

${ }^{a}$ Determined gravimetrically. ${ }^{b}$ Calculated using eqn (6) (see the Experimental section). ${ }^{c}$ By SEC in NMP $+0.05 \mathrm{M}$ LiBr using linear PS standards for calibration. ${ }^{d}$ By SEC in $20 \% \mathrm{CH}_{3} \mathrm{CN}$ in $0.05 \mathrm{M} \mathrm{Na}_{2} \mathrm{SO}_{4}$ in $\mathrm{H}_{2} \mathrm{O}$ with a MALLS detector. ${ }^{e}$ End group functionality according to UV/VIS spectroscopy. ${ }^{f}$ Not determined because polymer aggregates in aqueous eluent. ${ }^{g}$ From SANS in THF-d8, obtained with eqn (4). ${ }^{h}$ Radius of gyration obtained by fitting the SANS data from solutions in THF-d8 with eqn (2).

( $c f$. Fig. 2 below). Thus, additional SEC measurements were run with a second set-up, using an aqueous eluent $\left(20 \% \mathrm{CH}_{3} \mathrm{CN}\right.$ in $0.05 \mathrm{M} \mathrm{Na}_{2} \mathrm{SO}_{4}$ ) and multi-angle laser light scattering (MALLS) detection, which allows for the determination of absolute molar masses. Under these conditions, polymers with long chain lengths of DMA ( $\left.\mathrm{DP}_{n} \geq 250\right)$ and short end groups (C4 and C12) gave reliable results, with apparently only negligible fractions of aggregated polymer in the aqueous eluent. However, shorter polymers and polymers with octadecyl, i.e. with the most hydrophobic end groups, were found to aggregate and/or to interact with the column material, precluding from a meaningful analysis by this set-up. We noted that the molar masses determined using the SEC-MALLS set-up typically show slightly higher values than the theoretically expected values of $M_{\mathrm{n}}{ }^{\text {theo }}$. This finding can be due to the discrimination of smaller molar masses by MALLS detection, ${ }^{59}$ leading to some overestimation for $M_{\mathrm{n}}{ }^{\text {MALLS }}$. As $M_{\mathrm{w}}{ }^{\text {MALLS }}$ values are nevertheless good within precision, this implies that PDI ${ }^{\mathrm{MALLS}}$ values may underestimate somewhat the true polymer dispersities. ${ }^{59}$ Indeed, the PDI values derived from the set-up in NMP (based on calibration by polystyrene standards) are systematically higher than the ones derived from the set-up using MALLS detection. Nevertheless, molar mass distributions were found to be narrow $(<1.2)$ by either set-up (Table 1). Thus, the combined results of both SEC set-ups indicate the well-controlled character of the polymerisation.

As the Z-groups of the CTAs form the hydrophobic part in the amphiphilic PDMA and are therefore a key molecular parameter for the self-assembly in water, preservation of these end groups during polymerisation is vital. In order to probe the degree of end group functionality, all samples were analyzed by UV/VIS spectroscopy. The trithiocarbonate moiety in the $\mathrm{Z}$ group shows a prominent absorption band around $309 \mathrm{~nm}(\varepsilon \approx 10000$ to $20000 \mathrm{~L} \mathrm{~mol}^{-1} \mathrm{~cm}^{-1}$ ) and is thus suited for molar mass determination by end group analysis. ${ }^{\mathbf{5 0 , 6 0 , 6 1}}$ Assuming that every polymer holds the same number of trithiocarbonate moieties as the employed CTA, the number average molar mass is calculated using eqn (1). For well-controlled polymerisation this method leads to reliable results. ${ }^{50}$ However, any termination event will reduce the number of trithiocarbonate moieties, and consequently, will make the calculated values of $M_{\mathrm{n}}{ }^{\mathrm{UV}}$ increasingly overestimating the true values of $M_{\mathrm{n}}$. Thus, the comparison of $M_{\mathrm{n}}{ }^{\text {UV }}$ to $M_{\mathrm{n}}{ }^{\text {MALLS }}$ (or to $M_{\mathrm{n}}{ }^{\text {theo }}$ when SEC-MALLS could not be performed) will reveal the degree of end group functionality.

Noteworthy, the synthesis of the PDMA stars combines high yields (typically $\geq 85 \%$ ) and effective preservation of $Z$ end groups (end group functionality in most cases $\sim 90 \%$, see Table 1 ). This finding is rather unusual, because the longer the polymerisation proceeds, the more termination events will happen. Possibly, the high structural control up to high conversion can be explained by the observation that the reaction mixtures became very viscous in the course of polymerisation. As termination is a diffusion controlled process and hence its kinetics are governed by the viscosity of the solution, high viscosity slows termination down and thus prevents both the formation of star-star couples and unfunctionalized chain ends.

In Table 1 we also list the molar masses $M_{\mathrm{w}}$ sans as determined from SANS experiments (for details see ESI $\dagger$ ) of three different concentrations of polymers dissolved in THF-d8. The $M_{\mathrm{w}}{ }^{\text {sANs }}$ values (Table 1) agree reasonably well with $M_{\mathrm{w}}{ }^{\text {MALLs }}$, being on average systematically about $10-20 \%$ higher. The radii of gyration $R_{\mathrm{g}}$ range from 7.4 to $14.1 \mathrm{~nm}$ and are directly proportional to the molecular weight of the polymers.

The SEC-MALLS measurements provide direct evidence for the formation of star structures. As a star polymer has a more compact structure compared to a linear polymer of the same molar mass, a star polymer will elute later in SEC than its linear analogue. Fig. 1 shows the plot of $M_{\mathrm{w}}{ }^{\text {MALLS }}$ over elution volume $V$. In agreement with theory, the plot shows an increasing elution volume with increasing number of arms of the polymer. The linear correlation of $M_{\mathrm{w}}$ and $V$ over a wide elution range indicates uniform structures, meaning that the arms in one star 


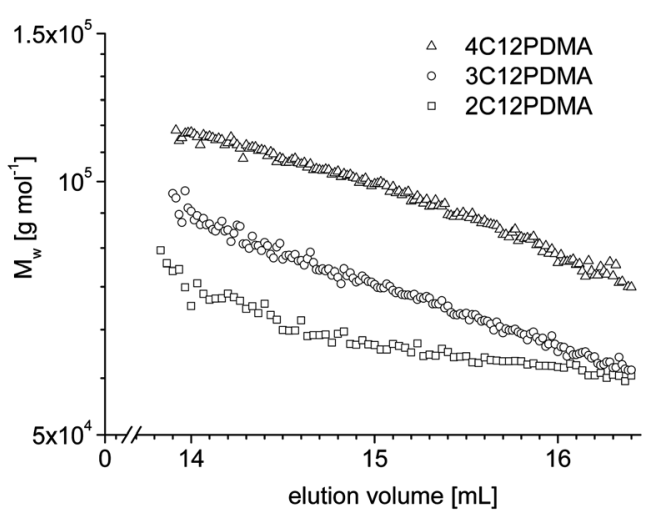

Fig. $1 M_{\mathrm{w}}$ (SEC-MALLS) of linear ( $\square$, entry 3 from Table 1), 3-arm $(\bigcirc$, entry 9 from Table 1$)$ and 4-arm $(\triangle$, entry 15 from Table 1$)$ star polymers over elution volume.

polymer molecule are of about the same length. Therefore, all indications from molecular analysis corroborate the successful preparation of well-defined star polymers.

To test the scope and limits of the PDMA star systems, we performed a set of polymerisations with increasing ratios of monomer to CTA, thus increasing the molar mass of the polymers prepared. The results of these experiments are plotted as apparent molar mass $M_{\mathrm{n}}$ app as found by SEC in NMP over theoretically expected molar mass $M_{\mathrm{n}}$ theo as calculated using eqn (6) (Fig. 2). While the absolute values fit rather well for lower molar masses, the deviation between $M_{\mathrm{n}}^{\text {app }}$ and $M_{\mathrm{n}}^{\text {theo }}$ increases with increasing molar mass. This behaviour is in analogy to the results of Table 1 discussed above. Additionally, Fig. 2 shows a small, but nevertheless notable increase of polymer dispersity with increasing molar mass. This is a priori expected, as decreasing amounts of CTA lead inevitably to less control over the polymerisation. In any case, this plot shows that the PDMA system works very well (at least up to molar masses of $100000 \mathrm{~g}$ $\mathrm{mol}^{-1}$ ) for the preparation of well-defined amphiphilic star polymers.

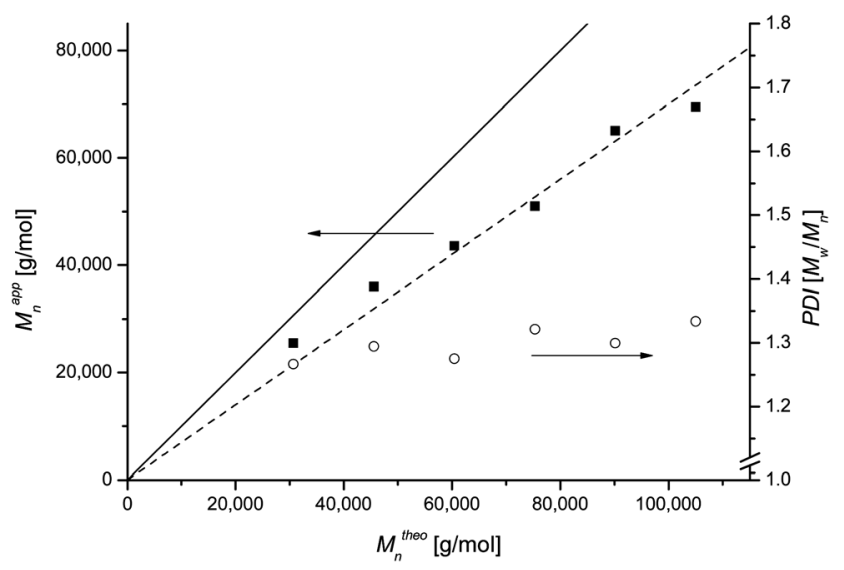

Fig. 2 Apparent molecular weight $M_{\mathrm{n}}^{\text {app }}(\mathbf{\square})$ and PDI ( $\left.\bigcirc\right)$ (from SEC in $\mathrm{NMP}+0.05 \mathrm{M} \mathrm{LiBr}$, calibrated with linear PS-standards) over theoretically expected molar mass $M_{\mathrm{n}}^{\text {theo }}$ for 3C12-PDMA star polymers with aspired arm lengths of 100, 150, 200, 250, 300 and 350. The straight line (-) marks the expected evolution of molar mass, the dotted line $(\cdots)$ is a guide for the eye.

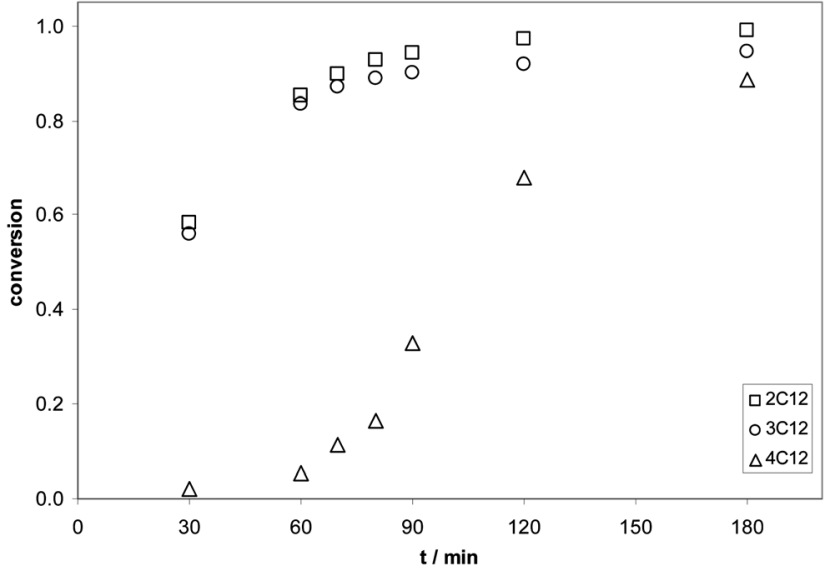

Fig. 3 Kinetic plot for the polymerisation of DMA using 2C12- ( $\square$ ), $3 \mathrm{C} 12$ - $(\bigcirc)$ and $4 \mathrm{C} 12-\mathrm{CTAs}(\triangle)$. Error bars $( \pm 5 \%$ conversion $)$ are omitted for the sake of clarity.

In order to learn more about the polymerisation of DMA in our system, we conducted kinetic experiments employing 2-, 3and 4-arm dodecyl-CTAs (2C12, 3C12 and 4C12, see Scheme 1), as illustrated in Fig. 3. The evolution of conversion over time demonstrates that the polymerisation of DMA is fast, reaching $60 \%$ conversion of the monomer after 30 minutes of polymerisation time for 2C12- and 3C12-CTAs. Polymerisation is complete after $2 \mathrm{~h}$. This corroborates the usefulness of DMA for the well-controlled production of star polymers. For the polymerisation using 4C12-CTA however, an induction period of about $60 \mathrm{~min}$ is clearly visible. This induction period can be explained by the peculiar molecular structure of the CTA, bearing two trithiocarbonate moieties in ortho-position at the phenyl ring. Once one of the positions is activated by the initial attack of the RAFT scheme, the neighbouring group can deactivate it, leading to the formation of a stable 7-membered cyclic radical (see Scheme 3). In the early stages of polymerisation the probability for this intramolecular addition can be as high as $99.9 \%$, according to a study on the polymerisation of styrene with multifunctional dithioesters of analogous molecular structure. ${ }^{29}$ Still, as this is a reversible equilibrium, the stable radical will open again, allowing for propagation. ${ }^{62}$ Consequently, almost complete conversion of DMA is finally achieved after $3 \mathrm{~h}$ of polymerisation with 4C12-CTA (Fig. 3). Note that all molar mass distributions obtained for the 4-arm star polymers are narrow and monomodal, indicating that the induction period has no consequences on the final outcome of the polymerisation.

In summary, we established conditions that allow the one-step synthesis of well-defined amphiphilic star polymers from DMA in high yield with excellent control over structure, molar mass and end group functionality. This enabled us to investigate the association behaviour of such amphiphilic stars in dependence on the various structural parameters.

\section{Self-assembly of the polymers in aqueous solution}

Due to the long hydrophilic DMA blocks that are common to the polymers prepared, all of them are well soluble in water, and thus, their behaviour in aqueous solution could be characterized by means of rheology, DLS, and SANS. Depending on the length 


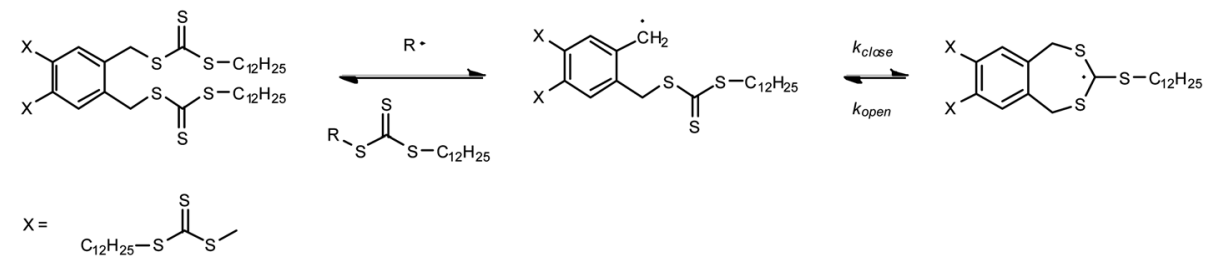

Scheme 3 Hypothetical formation of a stable radical at the early stages of the polymerisation using 4-arm CTAs from Scheme 1, as exemplified for 4C12-CTA.

of the alkyl end groups incorporated, hydrophobic aggregation is expected as it is known for previously studied linear and star like hydrophobically end-capped polymers. ${ }^{1,3,16,35,63-66}$

SANS experiments were exemplarily done on $1 \mathrm{wt} \%$ and $5 \mathrm{wt} \%$ solutions of polymer samples with dodecyl stickers (entries 4, 10 and 15, see Table 1) in order to learn about their structure in aqueous solution. The scattering curves (Fig. 4) in $\mathrm{D}_{2} \mathrm{O}$ show similar scattering patterns for the various polymers at a given concentration. Therefore, the number of arms apparently has little impact on their supramolecular structure, at the length scale under investigation. All samples exhibit scattering patterns as typically observed for spherically symmetric aggregates. In the case of the more concentrated solutions, the aggregates interact repulsively as indicated by a correlation peak. Most probably the hydrophilic polymer chains, which present a much larger volume fraction than the end groups in particular as the PDMA will be strongly hydrated, introduce significant repulsive interaction into this system. The attractive part of the interaction due to bridging is overwhelmed by an effective repulsive interaction due to the numerous surrounding hydrophilic chains, which give rise to substantial steric hindrance. The mean spacing of the aggregates was calculated from the position of the peak (see Table 2). This distance may be compared to the radius of gyration $R_{\mathrm{g}}$ of a star polymer which can be calculated as: ${ }^{67}$

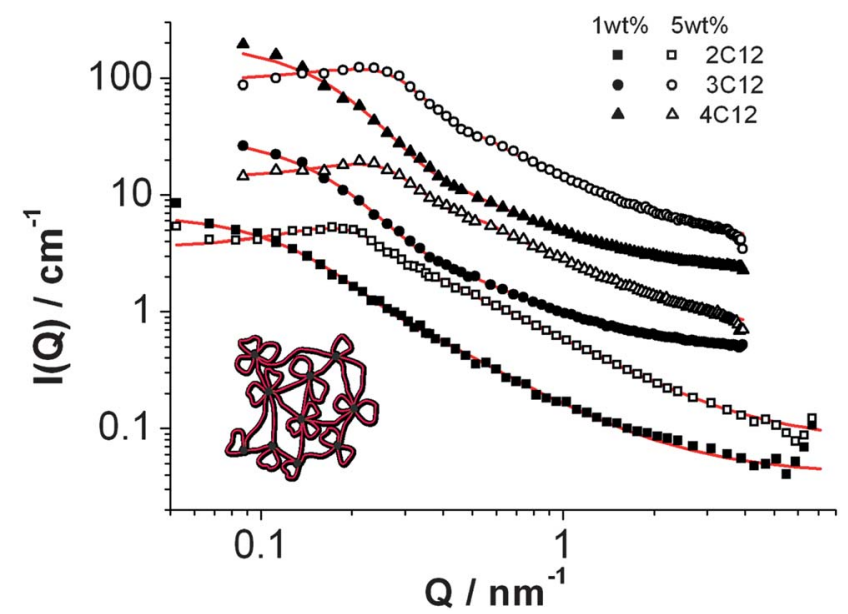

Fig. 4 SANS patterns of the aggregates of 2C12-PDMA ( $\square$, entry 4 in Table 1), 3C12-PDMA ( $\bigcirc$, entry 10$)$ and 4C12-PDMA ( $\triangle$, entry 15$)$ at concentrations of 1 and $5 \mathrm{wt} \%$ in $\mathrm{D}_{2} \mathrm{O}$ at room temperature. The absolute intensity is correct for both 2C12-PDMA curves, subsequent curves are multiplied by a factor $2 n$ for better visibility. The lines correspond to the fitted curves with a star form factor and a hard sphere structure factor (eqn (8)-(10)). The first two curves (2C12-PDMA) are from SANS2D and the rest from PAXY.

$$
R_{\mathrm{g}}^{2}=\left(3-\frac{2}{f}\right) \frac{C_{\infty}(N / f) b^{2}}{6}
$$

where $N$ is the total number of monomer units in the polymer, $b$ is the length of the monomer, $f$ is the number of arms in the star and $C_{\infty}$ is a correction constant (accounting for the local stiffness of the polymer chain) that is 9.3 for PDMA in water. ${ }^{68}$ The mean spacing of the aggregates decreases with the radius of gyration of the polymer. Assuming a cubic packing of the aggregates (around the hydrophobic cores), we can obtain the number of the dodecyl chains per micelle $\left(N_{\mathrm{St}}\right)$ (see Table 2) and therefore the average number of polymer molecules associated with one micelle $\left(N_{\text {agg }}\right)$ directly from the position of the correlation peak.

Assuming that the polymers self-assemble into flower-like micelles (inset of Fig. 4) that interact with a spherically symmetric potential, the scattering intensity can be approximated as

$$
I(Q)={ }^{1} N V^{2} \Delta \rho^{2} P(Q) S(Q)
$$

where ${ }^{1} N$ is the number density of scatterers, $V$ their volume, $\Delta \rho$ the difference between the coherent scattering length density of the micellar unit and the one of the solvent, $P(Q)$ the form factor, and $S(Q)$ the structure factor that takes into account the interactions between the aggregates. In order to describe the conformational structure of the aggregates we employed a form factor for a star proposed by Fetters et al. ${ }^{69}$ which has been commonly used to describe the structure of flower-like micelles formed by telechelic polymers: ${ }^{70-72}$

$$
{ }^{1} N V^{2} \Delta \rho^{2} P_{\text {star }}(Q)=I(0) \mathrm{e}^{-\frac{1}{3} Q^{2} R_{\mathrm{g}}^{2}}+\frac{4 \pi \alpha}{Q \xi} \frac{\sin \left[\mu \tan ^{-1}(Q \xi)\right]}{\left[1+Q^{2} \xi^{2}\right]^{\mu / 2}} \Gamma(\mu)
$$

The first term of eqn (9) is the Guinier approximation of the scattering intensity of the aggregates with radius of gyration $R_{\mathrm{g}}$, and forward scattering $I(0)$ defined by the scattering of the dried volume of polymer given by ${ }^{1} N V^{2} \Delta \rho^{2}$. The second term accounts for the monomer-monomer correlations with $\alpha$ being the scale parameter, $\xi$ the correlation length inside the star, and $\mu=1 / \nu-1$ where $\nu$ is the excluded volume parameter and $\Gamma(\mu)$ is the gamma function of argument $\mu$. To account for the repulsive interactions, a hard sphere structure factor, $S\left(Q, R_{\mathrm{HS}}, \phi_{\mathrm{HS}}\right)$, in the Percus-Yevick approximation ${ }^{73}$ was employed, where $R_{\mathrm{HS}}$ is the effective hard sphere radius that defines the interaction length and their volume fraction $\left(\phi_{\mathrm{HS}}\right)$ is determined by the number density ${ }^{1} N$ of hydrophobic cores given by:

$$
\phi_{\mathrm{HS}}={ }^{1} N V=\frac{4}{3} \pi R_{\mathrm{HS}}{ }^{3} \frac{N_{\mathrm{AV}} C_{\mathrm{wSt}}}{M_{\mathrm{St}} N_{\mathrm{St}}}
$$


Table 2 Parameters calculated from the position of the peak: $N_{\mathrm{agg}}, N_{\mathrm{St}}$, and $R_{\text {core }}$ and parameters derived from the detailed fits: $R_{\mathrm{G}}, \xi$ and $R_{\mathrm{HS}}$. Entry numbers refer to Table 1

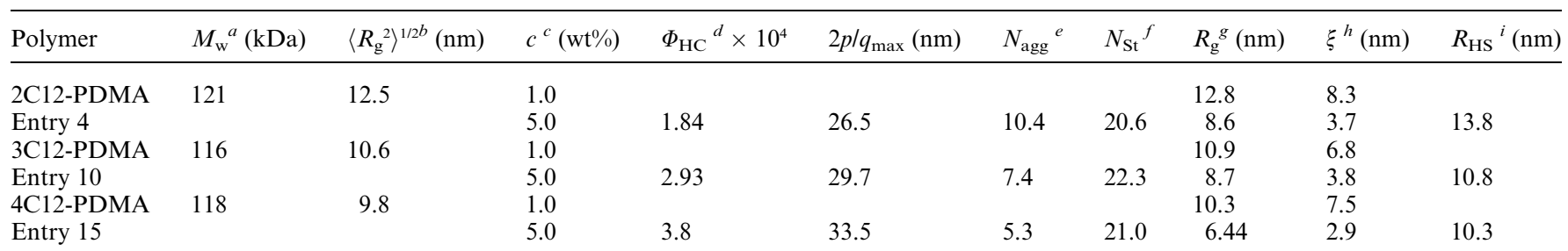

${ }^{a}$ By MALLS-SEC in water-acetonitrile. ${ }^{b}$ Radius of gyration calculated from eqn (7). ${ }^{c}$ Concentration of polymer in $\mathrm{D}_{2} \mathrm{O} .{ }^{d}$ Volume fraction of the dodecyl stickers. ${ }^{e}$ Aggregation number (per polymer molecule). ${ }^{f}$ Aggregation number of the stickers. ${ }^{g}$ Radius of gyration. ${ }^{h}$ Correlation length inside the star. ${ }^{i}$ Hard sphere radius.

where $N_{\mathrm{Av}}$ is the Avogadro number and $C_{\mathrm{wSt}}, M_{\mathrm{St}}$, and $N_{\mathrm{St}}$ are the weight concentration, molecular weight and the aggregation number of the stickers, respectively. According to eqn (10), the volume fraction $\phi_{\mathrm{HS}}$ and the hard sphere radius $R_{\mathrm{HS}}$ are directly related to each other and enter only as one additional fit parameter which is the aggregation number $N_{\mathrm{St}}$. One observes that $R_{\mathrm{HS}}$ (Table 2) is closely related to the length of the polymer.

This model fits our experimental data rather well (Fig. 4) and accordingly seems to be an accurate description of the structural situation. Apparently the hydrophobic domains, as described by $N_{\text {St }}$, remain constant in size irrespective of the number of arms. This implies that the tendency for aggregation is independent of the number of arms and apparently driven by the hydrophobic sticker. This means that the head group area per sticker in the aggregate is unaffected by the architecture of the polymer, as may be expected. In contrast, the $R_{\mathrm{g}}$ values that also include the effective polymer shell around such a hydrophobic core become smaller with increasing concentration, which corroborates the picture of forming more compact aggregates in this case. The repulsion between the aggregates is apparently directly linked to the amount of water-soluble polymer chains and therefore basically identical for the samples shown here, as the polymer concentration is very similar.

At concentrations higher than the overlap concentration, the aggregation number is expected to increase as a consequence of the repulsion between the hydrophilic chains and at the same time the probability of bringing hydrophobic stickers together rises correspondingly. ${ }^{74}$ It is interesting to note that $N_{\mathrm{St}}$ remains constant regardless of the number of arms of the polymer. This confirms that the free energy to form loops is irrelevant in the self-assembling process when the aggregation number is large enough as reported by Séréro et al. ${ }^{70}$

In order to obtain further insight into the structural and dynamical properties of these end-capped star polymers in aqueous solution, DLS measurements on 1 and $5 \mathrm{wt} \%$ solutions of the same samples (4,10 and 15) were done. The obtained intensity correlation functions $g^{2}(t)$ are shown in Fig. 5. The curves of samples with $1 \mathrm{wt} \%$ polymer exhibit an apparently rather simple decay, where the characteristic time is shifted to larger times with increasing number of arms. Nonetheless, the CONTIN analysis (see Fig. S2 $\dagger$ ) yields a rather complex distribution function of the decay times, where the maximum moves to larger times with the number of arms. Although this analysis must be taken with some care given the proximity of the maxima, it appears that there are 3 relaxation modes where the relative amplitudes change with the architecture of the polymer. Additionally, a comparison of mono-exponential, a stretched exponential and a bi-exponential fit (see Fig. S3†) shows that the correlation function results from the sum of at least two diffusive modes, as both show a $q^{2}$ dependence. Therefore, the curves were analyzed as a sum of two decaying exponential functions. The two effective diffusion coefficients (Table 3 ) correspond to the coexistence of small objects of $17 \mathrm{~nm}$ and of larger ones of around $200 \mathrm{~nm}$. The fraction of larger aggregates increases with the number of arms (see Fig. S4 $\dagger$ ). Also, the scattered intensity (listed in Table 3) increases with the number of arms supporting this idea. The hydrodynamic radii of the smaller-sized aggregates are in rather good agreement with the $R_{\mathrm{g}}$ obtained by SANS (Table 2). The somewhat larger value for the hydrodynamic radius is presumably due to the slowing down of the diffusion process by the PDMA corona of these aggregates.

In the case of $5 \mathrm{wt} \%$ samples one observes an even much more complex relaxation behaviour that extends over more than 5 orders of magnitude in time. Such complex relaxation patterns are frequently observed for polymeric networks, but have also

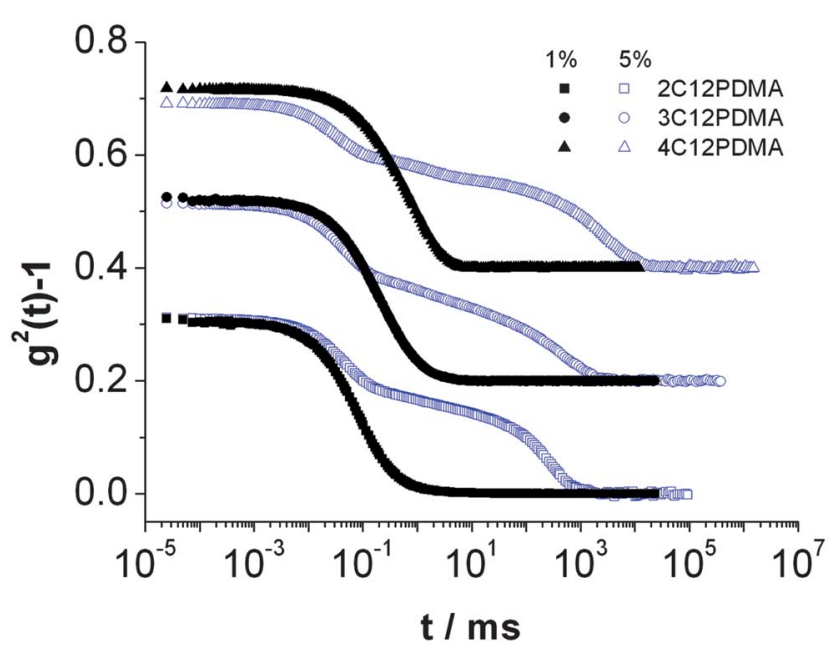

Fig. 5 Intensity correlation function $g^{2}(t)-1$ as a function of time for 1 and $5 \mathrm{wt} \%$ solutions of 2C12-PDMA $(\square / \square, 121 \mathrm{kDa}), 3 \mathrm{C} 12$-PDMA $(\mathrm{O} / \bullet, 116 \mathrm{kDa})$ and $4 \mathrm{C} 12$-PDMA $(\triangle / \triangle, 118 \mathrm{kDa})$ in water at a scattering angle of $90^{\circ}$ and a temperature of $25^{\circ} \mathrm{C}$ (curves are corrected for 2C12-PDMA and shifted upwards by adding 0.2 or 0.4 to the corresponding curves). 
Table 3 Parameters obtained from DLS, SLS and rheology for the samples of 2C12-PDMA, 3C12-PDMA, and 4C12-PDMA for 1 and 5 wt $\%$ concentration. Entry numbers refer to Table 1

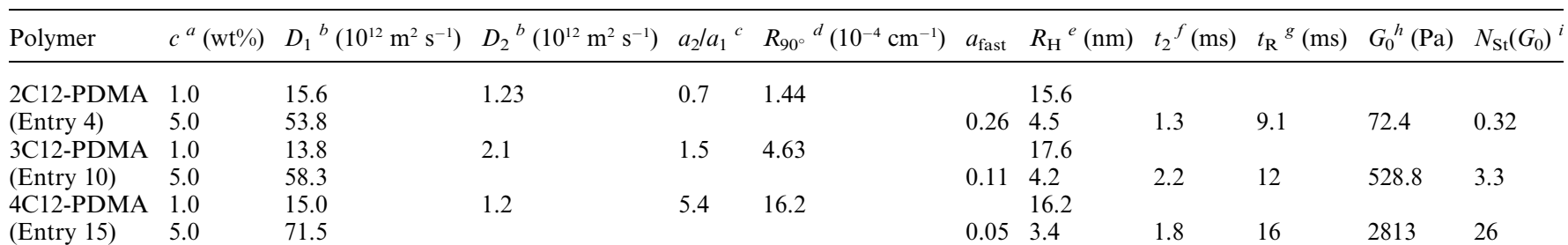

${ }^{a}$ Polymer concentration. ${ }^{b}$ Diffusion coefficients. ${ }^{c}$ Relative amplitude of the second diffusive mode for eqn (8). ${ }^{d}$ Rayleigh ratio. ${ }^{e}$ Hydrodynamic radius obtained from $D_{1} \cdot{ }^{f}$ Relaxation time of the intermediate relaxation mode as obtained from eqn $(8) .{ }^{g}$ Structural relaxation time. ${ }^{h}$ Plateau elastic modulus. ${ }^{i}$ Aggregation number obtained from $G_{0}$.

been seen for water-in-oil microemulsion droplets that are crosslinked by amphiphilic polymers. ${ }^{75}$ In our case, the relaxation always proceeds via three clearly separated modes, as similarly observed before in the case of the classical associative telechelic $\mathrm{C}_{12} \mathrm{EO}_{460} \mathrm{C}_{12}{ }^{2}{ }^{2}$ This demonstrates that one does not observe a simple diffusion process here, but the complex behaviour has to be associated with the network formed by the polymers in solution. Previous studies on model networks formed by simple telechelic polymers showed similarly three relaxation modes, where the fast one is associated with the droplet diffusion, the intermediate one is independent of $q$, and the slow one is typically also diffusive. ${ }^{76,77}$

For the $5 \mathrm{wt} \%$ samples the $g^{2}(t)$ data were fitted to a sum of one simple exponential and two stretched exponential functions:

$$
g^{2}(t)-1=\left[a_{1} \mathrm{e}^{-t / \tau_{1}}+a_{2} \mathrm{e}^{\left(-t / \tau_{2}\right)^{\beta_{1}}}+a_{3} \mathrm{e}^{\left(-t / \tau_{3}\right)^{\beta_{3}}}\right]^{2}
$$

From the angular dependence of the relaxation times (Fig. 6) we can conclude that the fast relaxation is purely diffusive as shown by its $q^{-2}$ dependence. The effective collective diffusion coefficients are larger than what is expected from the size of the aggregates obtained by means of SANS. This is typical for repulsive interaction which enhances collective diffusion substantially compared to the non-interacting case. ${ }^{78}$ The intermediate relaxation mode is almost independent of $q$, while the

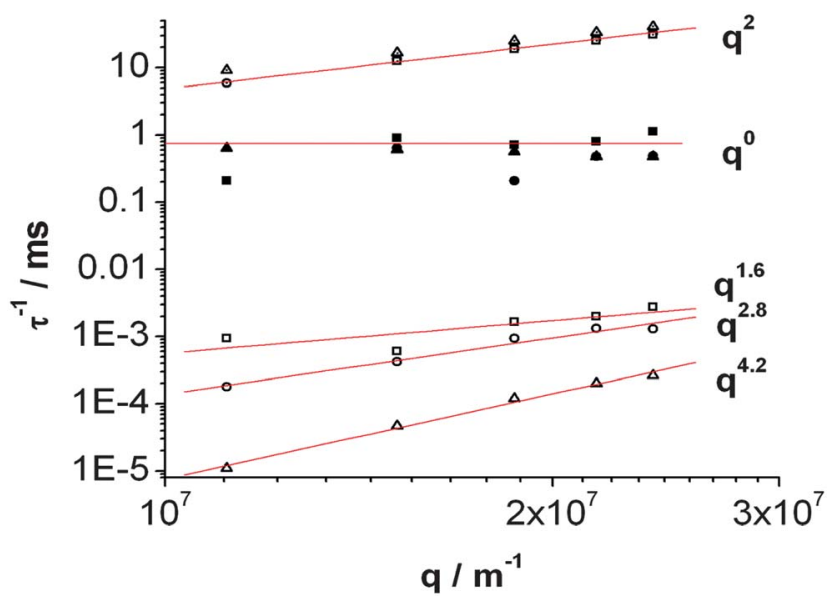

Fig. $6 q$ dependency of the three relaxation times for $5 \mathrm{wt} \%$ solutions of 2C12-PDMA (squares), 3C12-PDMA (circles), and 4C12-PDMA (triangles). slow relaxation mode shows a rather strong dependency with the scattering vector, following a power law of $2-4$, the exponent increasing substantially with increasing number of arms. Such behaviour is characteristically observed for viscoelastic networks with physical cross-links. ${ }^{79,80}$ Interestingly, the slower modes become more prominent when going from the 2-arm to the 4-arm polymer. This indicates that the tendency for aggregation increases with the number of arms. In particular, the intermediate relaxation mode, which is independent of $q$, becomes more pronounced. This mode appears to be linked to the rheological properties of the samples (see Fig. 7) and its characteristic time appears to be directly related to the rheological relaxation time $\left(\tau_{R}\right)$. Thereby it would be a direct measure of the elastic properties of the formed networks.

The samples with $1 \mathrm{wt} \%$ polymer show low viscosity. At $5 \mathrm{wt} \%$, a network is formed as already observed by SANS and DLS and the samples are highly viscous. In order to gain further information about their rheological behaviour the frequency dependent viscoelastic properties of these transient networks were determined by oscillatory shear experiments over an extended frequency range with a particular emphasis on the high frequency range. The obtained values for storage modulus $G^{\prime}$ and

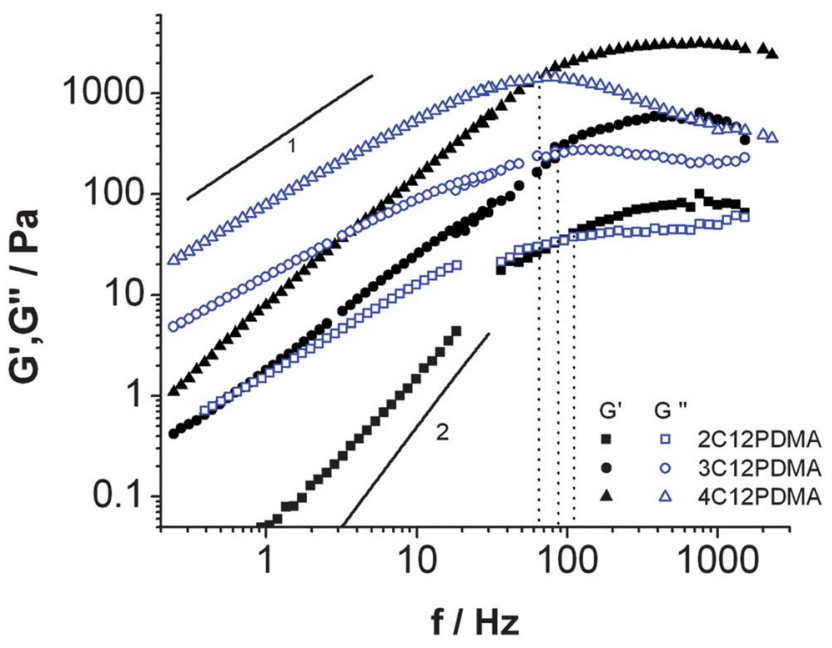

Fig. 7 Storage modulus $\left(G^{\prime}\right)$ and loss modulus $\left(G^{\prime \prime}\right)$ as a function of the frequency $(f)$ for $5 \mathrm{wt} \%$ solutions of $2 \mathrm{C} 12(\square / \mathrm{n}, 121 \mathrm{kDa}), 3 \mathrm{C} 12(\mathrm{o} / \bullet$ $116 \mathrm{kDa})$ and $4 \mathrm{C} 12(\triangle / \mathbf{\Delta}, 118 \mathrm{kDa})$ PDMA in water at room temperature. The lines indicate the respective power of 1 and 2 predicted by the Maxwell model. 
loss modulus $G^{\prime \prime}$ are given in Fig. 7. Both moduli are increasing for lower frequencies but not with the power law of 2 and 1 , respectively, as predicted by the Maxwell model. Accordingly, these are not simple rheological systems, but $G^{\prime}$ nonetheless effectively approaches a plateau value for frequencies above $100 \mathrm{~Hz}$.

The crossover point of $G^{\prime}$ and $G^{\prime \prime}$ can be taken for determining the characteristic rheological relaxation time, which increases from 9 to $16 \mathrm{~ms}$ when going from the 2-arm to the 4-arm polymer. This time is of the same order of magnitude as the $q$-independent intermediate relaxation process of DLS, thereby indicating that here the same process is monitored and they follow exactly the same tendency. At the same time, the plateau value of the elastic modulus $G_{0}$ increases from 79 to $2800 \mathrm{~Pa}$. This shows that with increasing number of arms the relaxation process becomes slower and at the same time the elastic properties of the network increase substantially.

According to a simple network theory, ${ }^{26}$ the high frequency storage modulus is given by $G_{0}={ }^{1} N k_{\mathrm{B}} T$, where ${ }^{1} N$ is the number density of elastically connected points. This theory can be applied to the experimental data and from the number density ${ }^{1} N$ one can calculate the corresponding theoretical number of elastic chains per aggregate (see Table 3 ).

Both DLS and rheology show that the polymers with more arms show a higher preference for interaggregate association than for intraaggregate association, i.e. for forming networks. In addition, the increase of the shear modulus $G_{0}$ apparently is directly related to the increase of the amplitude of the intermediate relaxation process observed in DLS which demonstrates that they are directly linked to each other and occur with the same characteristic time.

\section{Conclusion}

The combined results of polymer characterisation, i.e., ${ }^{1} \mathrm{H}$ NMR spectroscopy to follow conversion of the monomer, UV/VIS spectroscopy to probe the degree of end group functionalisation, and SEC to obtain the molecular weight distribution demonstrate the successful preparation of well-defined, hydrophobically end-capped, amphiphilic star polymers in one step from $N, N$-dimethylacrylamide and designed hydrophobic multifunctional RAFT agents. SANS studies of these highly water-soluble polymers revealed that their end-groups self-assemble in aqueous solution. While at lower concentrations flower-like micelles seem to exist, higher concentrations resulted in the formation of a transient network of polymer micelles. However, SANS did not show a peculiar effect of the number of arms of the star polymers on the structure of the networks, so that e.g. the number of hydrophobic dodecyl chains is constant at about 20, irrespective of the number of arms, i.e., the aggregation number is simply controlled by the packing conditions of the hydrophobic chains having a constant area requirement at the amphiphilic interface.

When looking into the dynamic properties of the networks using DLS and rheology, the number of arms and the tendency to form a network in between the micelles are correlated. DLS shows already a more complex behaviour for dilute (1 wt $\%$ ) samples, exhibiting a multi-modal relaxation, presumably due to the formation of clusters. The more concentrated $(5 \mathrm{wt} \%)$ and highly viscous samples show even 3 relaxation modes. While the first is diffusive and related to the size of the contained hydrophobic domains, the characteristic time of the second mode is independent of $q$, and the relaxation rates of the third mode show a power law dependence on $q$ that rises from 1.6 for the 2-arm polymer to 4.2 for the 4 -arm polymer. The second mode shows a similar timescale as the characteristic time of rheology, and both methods agree well in the general trend of the values found. Our initial hypothesis that a branched amphiphilic polymer might show a higher tendency to form a network than a linear analogue is thus confirmed for their behaviour in aqueous solution. Importantly, this behaviour does not affect the static structure seen by SANS, but it affects in a similar way both DLS measurements and rheological behaviour. Future work will be directed towards the question whether such polymers are suitable for exerting rheological control in microemulsions as well.

\section{Acknowledgements}

This work was funded by DFG grants GR1030/9-1 and LA611/ 8-1. We thank Marlies Gräwert and Helmut Schlaad (both Max Planck Institute of Colloids and Interfaces) for SEC measurements in NMP and Raphael Suminski (University of Potsdam) for kinetic experiments. For SANS beam time allocation we are grateful to ISIS at Rutherford Appleton Laboratory, Didcot and LLB, Saclay, and the SANS experiments were funded by the NMI3 EU program. For very valuable help with performing the SANS experiments we thank Laurence Noirez (LLB, Saclay). P.M.M. gratefully acknowledges a grant from DAAD-La Caixa.

\section{References}

1 T. Annable, R. Buscall, R. Ettelaie and D. Whittlestone, J. Rheol., 1993, 37, 695-726.

2 E. Alami, M. Almgren, W. Brown and J. François, Macromolecules, 1996, 29, 2229-2243.

3 M. Filali, M. J. Ouazzani, E. Michel, R. Aznar, G. Porte and J. Appell, J. Phys. Chem. B, 2001, 105, 10528-10535.

4 F. Laflèche, T. Nicolai, D. Durand, Y. Gnanou and D. Taton, Macromolecules, 2003, 36, 1341-1348.

5 A. M. Bivigou-Koumba, J. Kristen, A. Laschewsky, P. MüllerBuschbaum and C. M. Papadakis, Macromol. Chem. Phys., 2009, 210, 565-578.

6 J. Adelsberger, A. Kulkarni, A. Jain, W. Wang, A. M. BivigouKoumba, P. Busch, V. Pipich, O. Holderer, T. Hellweg, A. Laschewsky, P. Müller-Buschbaum and C. M. Papadakis, Macromolecules, 2010, 43, 2490-2501.

7 A. Bivigou-Koumba, E. Görnitz, A. Laschewsky, P. MüllerBuschbaum and C. Papadakis, Colloid Polym. Sci., 2010, 288, 499517.

8 C. Chassenieux, T. Nicolai and L. Benyahia, Curr. Opin. Colloid Interface Sci., 2011, 16, 18-26.

9 J. Adelsberger, E. Metwalli, A. Diethert, I. Grillo, A. M. BivigouKoumba, A. Laschewsky, P. Müller-Buschbaum and C. M. Papadakis, Macromol. Rapid Commun., 2012, 33, 254-259.

10 V. S. Kadam, E. Nicol and C. Gaillard, Macromolecules, 2012, 45, 410-419.

11 A. Miasnikova, A. Laschewsky, G. G. DePaoli, C. M. Papadakis, P. Müller-Buschbaum and S. S. Funari, Langmuir, 2012, 28, 44794490.

12 M. Gradzielski, A. Rauscher and H. Hoffmann, J. Phys. IV, France, 1993, 03, 65-79.

13 A. Tom, B. Richard, E. Rammile and W. Diane, J. Rheol., 1993, 37, 695-726.

14 S. Maccarrone, H. Frielinghaus, J. Allgaier, D. Richter and P. Lindner, Langmuir, 2007, 23, 9559-9562.

15 G. Tae, J. A. Kornfield, J. A. Hubbell and J. Lal, Macromolecules, 2002, 35, 4448-4457. 
16 S. Hietala, S. Strandman, P. Järvi, M. Torkkeli, K. Jankova, S. Hvilsted and H. Tenhu, Macromolecules, 2009, 42, 1726-1732.

17 L. J. Fetters, A. D. Kiss, D. S. Pearson, G. F. Quack and F. J. Vitus, Macromolecules, 1993, 26, 647-654.

18 N. Hadjichristidis, M. Pitsikalis, S. Pispas and H. Iatrou, Chem. Rev., 2001, 101, 3747-3792.

19 A. Gregory and M. H. Stenzel, Prog. Polym. Sci., 2012, 37, 38-105.

20 C. J. Hawker, A. W. Bosman and E. Harth, Chem. Rev., 2001, 101, 3661-3688.

21 K. Khanna, S. Varshney and A. Kakkar, Polym. Chem., 2010, 1, $1171-1185$.

22 M. Morton, T. E. Helminiak, S. D. Gadkary and F. Bueche, J. Polym. Sci., 1962, 57, 471-482.

23 T. A. Orofino and F. Wenger, J. Phys. Chem., 1963, 67, 566-575.

24 J. R. Schaefgen and P. J. Flory, J. Am. Chem. Soc., 1948, 70, 27092718.

25 T. Altares, D. P. Wyman, V. R. Allen and K. Meyersen, J. Polym. Sci., Part A: Gen. Pap., 1965, 3, 4131-4151.

26 J. Xia, X. Zhang and K. Matyjaszewski, Macromolecules, 1999, 32, 4482-4484.

27 A. Duréault, D. Taton, M. Destarac, F. Leising and Y. Gnanou, Macromolecules, 2004, 37, 5513-5519.

28 X. Hao, C. Nilsson, M. Jesberger, M. H. Stenzel, E. Malmström, T. P. Davis, E. Östmark and C. Barner-Kowollik, J. Polym. Sci, Part A: Polym. Chem., 2004, 42, 5877-5890.

29 H. Chaffey-Millar, M. H. Stenzel, T. P. Davis, M. L. Coote and C. Barner-Kowollik, Macromolecules, 2006, 39, 6406-6419.

30 S. Strandman and H. Tenhu, Polymer, 2007, 48, 3938-3951.

31 H. Gao and K. Matyjaszewski, Chem.-Eur. J., 2009, 15, 6107-6111.

32 A. D. Jenkins, R. G. Jones and G. Moad, Pure Appl. Chem., 2010, 82, 483-491.

33 G. Zheng and C. Pan, Polymer, 2005, 46, 2802-2810.

34 B. Grassl, L. Billon, O. Borisov and J. François, Polym. Int., 2006, 55, 1169-1176.

35 S. Hietala, P. Mononen, S. Strandman, P. Järvi, M. Torkkeli, K. Jankova, S. Hvilsted and H. Tenhu, Polymer, 2007, 48, 4087-4096.

36 H. Mori, H. Ookuma and T. Endo, Macromolecules, 2008, 41, 69256934.

37 M. H. Stenzel, Macromol. Rapid Commun., 2009, 30, 1603-1624.

38 W. Zhang, W. Zhang, N. Zhou, Z. Cheng, J. Zhu and X. Zhu, Polymer, 2008, 49, 4569-4575.

39 Q. Bian, Y. Xiao and M. Lang, J. Polym. Sci., Part A: Polym. Chem., 2011, 50, 571-580.

40 G. Moad, E. Rizzardo and S. H. Thang, Aust. J. Chem., 2009, 62, 1402-1472.

41 Handbook of RAFT Polymerization, ed. C. Barner-Kowollik, WileyVCH, Weinheim, Germany, 2008.

42 R. T. A. Mayadunne, J. Jeffery, G. Moad and E. Rizzardo, Macromolecules, 2003, 36, 1505-1513.

43 C. Barner-Kowollik, T. P. Davis and M. H. Stenzel, Aust. J. Chem., 2006, 59, 719-727.

44 M. H. Stenzel and T. P. Davis, J. Polym. Sci., Part A: Polym. Chem., 2002, 40, 4498-4512.

45 J. Bernard, A. Favier, L. Zhang, A. Nilasaroya, T. P. Davis, C. Barner-Kowollik and M. H. Stenzel, Macromolecules, 2005, 38, $5475-5484$.

46 C. Barner-Kowollik, T. P. Davis, J. P. A. Heuts, M. H. Stenzel, P. Vana and M. Whittaker, J. Polym. Sci., Part A: Polym. Chem., 2003, 41, 365-375.

47 S. Angot, D. Taton and Y. Gnanou, Macromolecules, 2000, 33, 54185426.

48 K. Skrabania, W. Li and A. Laschewsky, Macromol. Chem. Phys., 2008, 209, 1389-1403.
49 A. Samakande, R. D. Sanderson and P. C. Hartmann, Synth. Commun., 2007, 37, 3861-3872.

50 K. Skrabania, A. Miasnikova, A. M. Bivigou-Koumba, D. Zehm and A. Laschewsky, Polym. Chem., 2011, 2, 2074-2083.

51 F. Fischer, D. Zufferey and R. Tahoces, Polym. Int., 2011, 60, 1259 1262.

52 M. Barz, R. Luxenhofer, R. Zentel and M. J. Vicenta, Polym. Chem., 2011, 2, 1900-1918.

53 A. J. Convertine, B. S. Lokitz, A. B. Lowe, C. W. Scales, L. J. Myrick and C. L. McCormick, Macromol. Rapid Commun., 2005, 26, 791795.

54 P.-E. Millard, L. Barner, J. Reinhardt, M. R. Buchmeiser, C. BarnerKowollik and A. H. E. Müller, Polymer, 2010, 51, 4319-4328.

55 P. Malo de Molina, C. Herfurth, A. Laschewsky and M. Gradzielski, Prog. Colloid Polym. Sci., 2011, 138, 67-72.

56 P. J. Flory, Statistical Mechanics of Chain Molecules, Interscience, New York, 1969.

57 L. Kirschenmann and W. Pechhold, Rheol. Acta, 2002, 41, 362-368.

58 I. Degani, R. Fochi, A. Gatti and V. Regondi, Synthesis, 1986, 894 899.

59 J.-F. Baussard, J.-L. Habib-Jiwan, A. Laschewsky, M. Mertoglu and J. Storsberg, Polymer, 2004, 45, 3615-3626.

60 M. Päch, D. Zehm, M. Lange, I. Dambowsky, J. Weiss and A. Laschewsky, J. Am. Chem. Soc., 2010, 132, 8757-8765.

61 D. Zehm, A. Laschewsky, P. Heunemann, M. Gradzielski, S. Prévost, H. Liang, J. P. Rabe and J.-F. Lutz, Polym. Chem., 2011, 2, 137-147.

62 J. Hong, Q. Wang, Y. Lin and Z. Fan, Macromolecules, 2005, 38, 2691-2695.

63 Q. T. Pham, W. B. Russel, J. C. Thibeault and W. Lau, Macromolecules, 1999, 32, 2996-3005.

64 F. Renou, T. Nicolai, E. Nicol and L. Benyahia, Langmuir, 2008, 25, 515-521.

65 S. Strandman, A. Zarembo, A. A. Darinskii, P. Laurinmäki, S. J. Butcher, E. Vuorimaa, H. Lemmetyinen and H. Tenhu, Macromolecules, 2008, 41, 8855-8864.

66 M. Štěpánek, M. Uchman and K. Procházka, Polymer, 2009, 50, 3638-3644

67 M. Daoud and J. P. Cotton, J. Phys., 1982, 43, 531-538.

68 J. Brandrup, E. H. Immergut, E. A. Grulke, A. Abe and D. R. Bloch, Polymer Handbook, John Wiley \& Sons, Hoboken, New Jersey, 1999.

69 W. D. Dozier, J. S. Huang and L. J. Fetters, Macromolecules, 1991, 24, 2810-2814.

70 Y. Séréro, R. Aznar, G. Porte, J. F. Berret, D. Calvet, A. Collet and M. Viguier, Phys. Rev. Lett., 1998, 81, 5584-5587.

71 E. Beaudoin, O. Borisov, A. Lapp, L. Billon, R. C. Hiorns and J. François, Macromolecules, 2002, 35, 7436-7447.

72 C. Rufier, A. Collet, M. Viguier, J. Oberdisse and S. Mora, Macromolecules, 2011, 44, 7451-7459.

73 N. W. Ashcroft and J. Lekner, Phys. Rev., 1966, 145, 83-90.

74 T. M. Birshtein and E. B. Zhulina, Polymer, 1989, 30, 170-177.

75 T. Blochowicz, C. Gögelein, T. Spehr, M. Müller and B. Stühn, Phys. Rev. E: Stat., Nonlinear, Soft Matter Phys., 2007, 76, 041505.

76 M. Schwab and B. Stühn, J. Chem. Phys., 2000, 112, 6461-6471.

77 E. Michel, L. Cipelletti, E. d'Humieres, Y. Gambin, W. Urbach, G. Porte and J. Appell, Phys. Rev. E: Stat. Phys., Plasmas, Fluids, Relat. Interdiscip. Top., 2002, 66, 031402.

78 M. Gradzielski and H. Hoffmann, J. Phys. Chem., 1994, 98, 26132623.

79 B. Nyström, H. Walderhaug and F. K. Hansen, J. Phys. Chem., 1993, 97, 7743-7752.

80 I. Hoffmann, P. Heunemann, S. Prévost, R. Schweins, N. J. Wagner and M. Gradzielski, Langmuir, 2011, 27, 4386-4396. 